\title{
Methodological Approaches in Population Botany and Plant Ecology
}

\section{Svetlana Vladislavovna Fedorova}

Institute of Fundamental Medicine and Biology, Kazan (Volga Region) Federal University, Kazan, Russian Federation

\section{Email address:}

S.V.Fedorova@inbox.ru

\section{To cite this article:}

Svetlana Vladislavovna Fedorova. Methodological Approaches in Population Botany and Plant Ecology. American Journal of BioScience. Special Issue: Innovative Methodological Approaches in Botany and Plant Population Ecology. Vol. 8, No. 3, 2020, pp. 73-90. doi: 10.11648/j.ajbio.20200803.14

Received: May 16, 2020; Accepted: May 28, 2020; Published: June 20, 2020

\begin{abstract}
In the article presents a new Concept "Polycentric Model of Plant" in addition to the generally accepted in botany Concept "Morphologic Model of Plant". The basis of the development is laid by my many years of experience in conducting a population study of plants from different categories of the life form in different regions. Concept "Polycentric Model of Plant" allows a new structure of the body of the plant. Elements of the model are not organs, but functional centers: Shoot-formation center, Mineral-nutrition center, Organic-nutrition center, Generation center. Metric characteristics of each of these centers are indicators by which the researcher can simulate the direction of development of the plant population system in each of surveyed habitats. Presented new methodological approaches to solving pressing environmental problems within Population Botany and Plant Ecology, developed on the basis of Concept "Polycentric Model of Plant". These are: 1) Universal Scale of Vegetation Elements and Diagnostic Key for determining Vegetation Elements by a set of metric indicators of the most developed hypothetical individual of species in the composition of the plant community was developed; 2) Formula for calculate Coefficient Digression of Steppe Vegetation; 3) Scale of Digression Steppe Vegetation and Diagnostic Key to determining 5 stages on this scale; 4) Hypothetical Lifecycle of Plant from the category of life forms "Shrub" and Diagnostic Key to determining 7 stages in this cycle; 5) Diagnostic Key for structuring Plant Population System from the category of life forms "Stoloniferous" by Morph-function groups. Presented also: 1) Elements in "Polycentric Model of Plant", the functional role and the likely participation of one or another element in the formation of the product of vegetative and generative reproductions; 2) Hypothetical Lifecycle of Plant from categories of life forms "Terrestrial-stoloniferous" and "Soboliferous shrub" by example Potentilla anserina L. and Amygdalus nana L. (Rosaceae); 3) the complete set of Morph-functional groups of individuals as part of a plant population system, the functional role of each group and the likelihood of an individual falling into each group in Hypothetical Lifecycle of Plant from the category of life forms "Stoloniferous"; 4) results of a 3-year experiment with $P$. anserina, which reflecting population response to the climatic factor and the different of individual disposition presented in Concept "Polycentric Model of Plant"; 5) basic principles of plants population research and points of research on which it is expedient to involve gifted children.
\end{abstract}

Keywords: Concept Polycentric Model of Plant, Digression Steppe Vegetation, Lifecycle of Shrub, Stoloniferous Plant, Potentilla anserina, Amygdalus nana, Climatic Factor, Population Response

\section{Introduction}

In the middle of the 20th century, 2 new directions began to form in botany in connection with the development of a systematic approach: Population Botany and Plant Population Ecology. The object of research in classical Botany is a separate plant body, withdrawn from its usual habitat without taking into account information about this environment. The object of research in Population Botany is the multitude of such body that form, as a result of their life activity, self-developing and self-regulating systems of one species plant, taking into account information about environment. The object of research in Plant Population Ecology is the multitude of such body that form, as a result of their life activity, self-developing and self-regulating systems of different species plant, taking into account information about 
environment. Now, population directions are at the stage of forming a methodology. Critical views on the fundamental foundations of Botany formed in my brain on the basis of extensive experience in carrying out research work with different plant species that have a perennial development cycle, in different regions [1-25].

The purpose of this article is to formulate the fundamental principles conducting of plants population research for increasing the efficiency of solving environmental problems.

Tasks: 1) to describe Concept "Polycentric Model of Plant" in addition to the generally accepted Concept "Morphologic Model of Plant"; 2) to determine the location of the model element in the structure of the plant body from different categories of life form; 3) to submit a number of methodological developments, made on the basis of Concept "Polycentric Model of Plant"; 4) to describe the algorithm for conducting a population research based on the Concept "Polycentric Model of Plant" and highlight the stages of this process at which it is advisable to attract gifted children; 5) to submit a series of experimental research works, made on the basis of Concept "Polycentric Model of Plant".

\section{Two Concepts: "Morphologic Model of Plant" and "Polycentric Model of Plant"}

Concept "Morphologic Model of Plant" implies the body structuring the plant by external criteria. In this model, the hypothetical body of plant is organism, because the formed by a hierarchy of organs.

Organs are united into two main systems: the root and the shoot. These systems have a transition zone in which the internal structure of the plant organism changes in connection with the change in function. The main function of the root system is the formation of structures providing transportation the mineral solution from the environment to the plant body. The main function of the shoot system is the formation of structures providing: 1) assimilation; 2) transportation the organic solution; 3) genetic diversity and plant propagation over long distances; 4) resumption plants after exposure to unfavorable factor.

As the body of plant grows and develops, three functional zones are differentiated in the shoot system. 1. Renewal zone. Here, the buds of the plant are concentrated in three types (lateral buds having or not protective scales and adventitious ones). 2. Vegetative zone. Here, the buds of the plant are concentrated in five types (lateral and apical buds having or not protective scales and adventitious ones), and also the organs that ensure the organic nutrition of the plant (assimilating organs or organs that allow the organic substances to be sucked from the host's organism). 3 . Reproductive zone. Here, the organs are concentrated, the main function, which is connected with ensuring the reproduction process.

All organs of the plant are divided in two categories:
"Generative organ" and "Vegetative organ".

Category "Generative organ" includes the entire variety of organs that are capable of performing one of a number of functions to ensure the process of speciation and propagation of the plant: 1) gamete generation; 2) fusion of gametes; 3) formation of plant germ in the endogenous habitat; 4) isolation of the germ from the parental organism.

Category "Vegetative organ" includes all the variety of organs that are unable to perform any of the functions listed above. But, they are able to perform one of a number of functions to ensure the growth process of the plant body and the age change in the hierarchy of genetically identical clones: 1) absorption of a mineral or organic solution from the environment; 2) assimilation; 3) plant diaspore formation in the renewal zone or in the vegetative zone on the organism of plant; 4) stimulation of the development of such diaspore into an independent clone; 5) formation of a system between clones formation.

Concept "Morphological Model of Plant" contributed to development the science bio-morphology [26]. Bio-morphology allows you to order the entire variety of plant forms in a hierarchical series of categories. The largest of them are: "Tree", "Shrub", "Dwarf shrub", "Semifrutex or semishrub", "Dwarf semifrutex", "Perennial", "Biennial", "Annual".

There are a number of categories life forms that include species of perennial plants that have a potential capacity in ontogeny for formation of: 1) stolon then species of plants are combined into the category "Stoloniferous"; 2) underground shoot - into the category "Rhizomatous"; 3) root having an additional bud - into the category "Soboliferous or creeping-rooted"; 4) shoot, initially elongated orthotropic, later decumbent - into the category "Terrestrial-decumbent"; 5) over ground creeper shoot - into the category "Terrestrial-creeping". These categories are combined into a larger category "Vegetative-mobile". Those will be required later in the process of presenting the article.

Concept "Morphologic Model of Plant" works fine on the organism-level of organization of life. A detailed description of the organs makes it possible to more clearly visualize the image of the plant and limit one species of plant from another. This is very important at the stage of research on the diversity of the plant world [3, 4, 7, 9-15, 21-31]. However, deepening into the morphology of body plant fragments does not allow us to develop universal diagnostic tools that are necessary to solve environmental problems.

Concept "Polycentric Model of Plant" allows a new approach to structuring the body plant. Elements of the model are not organs, but functional centers. It is the: 1) Shoot-formation center; 2) Mineral-nutrition center; 3) Organic-nutrition center; 4) Generation center (Tables 1, 2, Figures 1, 2). In this model, hypothetical body plant is Polycentric System. The metric characteristics of each of these centers are indicators with which the researcher can model the development of Plant Population System in each of the surveyed habitats.. 
Table 1. Correspondence of elements in Polycentric Model of Plant and Morphologic Model of Plant.

\begin{tabular}{ll}
\hline Polycentric Model & Morphologic Model \\
\hline Shoot-formation center & $\begin{array}{l}\text { node in the zone of plant renewal (location in the system of organs: assimilating shoot, stolon, rhizome, tuber, } \\
\text { root-tuber, onion, corm, caudex) } \\
\text { base of the root system (location in the system of organs: transition zone between root and shoot systems) } \\
\text { Mineral-nutrition center }\end{array}$ \\
$\begin{array}{l}\text { assimilating organ (leaf blade, segment of a modified stem or leaf), haustorium (in a parasitic plant), leaf trap (in } \\
\text { predatory plant) } \\
\text { node in the reproductive zone of the shoot (authority: inflorescence, fragment of inflorescence, flower, bud, stem, } \\
\text { fruit, strobe, antheridium, archegonium, sporophyll, sporangium) }\end{array}$ \\
Generation center &
\end{tabular}

+ The node is the body plant fragment on which the buds are located closer than $0.4 \mathrm{~cm}$ along the length of the communications

Knowledge of natural variants of the plant population system of a particular species is an important step for the development of measures to restore the disturbed areas and rational use of plant resources

\section{Concept "Polycentric Model of Plant" - Tool for Structuring Plant Population System from Category "Terrestrial-stoloniferous"}

One of the representatives of the category of life forms "Terrestrial-stoloniferous" is herbaceous plants Potentilla anserina L. (Rosaceae). This plant is capable of forming several modifications of the shoot: 1) rosette shoot, 2) short orthotropic rhizome, 3) over ground stolon. Moreover, the stolon is an escape which is a part of the axis of the inflorescence, which either grows horizontal at once, or quickly lays on the soil.

The morphological feature of the stolon lies in the fact that it has two zones: stretch zone, formed elongated internode and braking zone, formed by extremely short internodes and closely spaced buds. The root of this plant is also able to form subordinate buds even if small fragments remain from the root in the soil. This phenomenon in plant life is called hemorhizogenesis. Thus, the plant is able to form root offspring and rapidly renew the population system of the species after mechanical action. This phenomenon was described by me earlier $[1,3,5,6]$, and will also be presented in this article later.

Figure 3 shows the scheme of Hypothetical Lifecycle of Plant from the category of life forms "Terrestrial-stoloniferous". The scheme consistently reflects all possible ontogenetic groups through which the development of an individual plant can go through: seedling (p), juvenile (j), immature (im), virginyle (v), generative (g), subsenile (ss), senile (s) $[29,30]$.

At stages in the range of ontogenetic groups "im-ss" an individual is capable of forming a stolon. At stages in the range of ontogenetic groups " $\mathrm{g}$-ss" an individual is capable of forming a generation center. However, in actual lifecycle a particular individual differently realizes its potential abilities, forming or not a stolon or a generation center. This fact allows us to structure the composition of the plant population system into 4 morph-functional groups. Thus, each individual on the path of the actual life cycle will fall into one of the morph-functional groups.

To assess the strategy of the plant population system, I combined all shoot-formation centers on the rhizome (the so-called branched rosette shoot) to combine and to apply the notion "Primary shoot-formation center". Also I combined all shoot-formation centers on a braking zone of stolon and to apply the notion "Secondary shoot-formation center". These steps allowed me to develop a clear key for structuring Plant Population System by 4 Morph-functional groups (Table 3). Each group performs certain functions as part of this system. The ratio between these groups is an important criterion for diagnosing the condition of a species in a specific habitat and for predicting its development. This methodological approach is universal for representatives of this life form. On its basis, I conducted a lot of research with various plant species in different environments and at different points of the range $[1,3,5-8,17,18]$.

\section{Concept "Polycentric Model of Plant" - Tool for Diagnosing Stage in Lifecycle of Plant from Category "Shrub"}

The methodological approach, which will lower the significance of the subjective component in the process of determining the stage in Lifecycle of Plant, is the most promising for widespread use in botanical and environmental practice. Theorists seek to establish a universal scale of the stages of the hypothetical lifecycle of a plant in order to increase the efficiency of diagnosis of the state of the habitat. I represent a methodological development in this area.

The diagnostic key for determining the stage in Lifecycle of Plant from the category of life forms "Shrub" was tested by me in the example of soboliferous plant Amygdalus nana L. (Rosaceae). Plant control samples (200 specimens) were inspected in 2012-2013. They grew in meadow and steppe formations on the slopes with exposure south, south-east and south-west. Type of soil: leached black earth of low power. 
Table 2. Elements in Polycentric Model of Plant: functional role and likely participation in the formation of vegetative and generative reproduction product.

\begin{tabular}{|c|c|c|c|c|}
\hline \multirow[t]{2}{*}{ Element } & \multirow{2}{*}{$\begin{array}{l}\text { Main functional role } \\
\text { the formation of: }\end{array}$} & \multirow[t]{2}{*}{ Additional functional role } & \multicolumn{2}{|c|}{$\begin{array}{l}\text { Probable participation in } \\
\text { the formation of } \\
\text { reproduction product: }\end{array}$} \\
\hline & & & vegetative & generative \\
\hline $\begin{array}{l}\text { Shoot-formation } \\
\text { center }\end{array}$ & $\begin{array}{l}\text { a reserve plant diaspores in case of } \\
\text { experiencing unfavorable factors; assimilation } \\
\text { system or organic absorption system }\end{array}$ & mineral absorption system & + & - \\
\hline $\begin{array}{l}\text { Mineral-nutrition } \\
\text { center }\end{array}$ & mineral absorption system & $\begin{array}{l}\text { a reserve plant rudiments in case of experiencing } \\
\text { unfavorable factors }\end{array}$ & + & - \\
\hline $\begin{array}{l}\text { Organic-nutrition } \\
\text { center }\end{array}$ & $\begin{array}{l}\text { assimilation system or organic absorption } \\
\text { system }\end{array}$ & $\begin{array}{l}\text { a reserve plant diaspores in case of experiencing } \\
\text { unfavorable factors; mineral absorption system }\end{array}$ & + & - \\
\hline Generation center & $\begin{array}{l}\text { reproductive system and plant germs for } \\
\text { distribution }\end{array}$ & $\begin{array}{l}\text { a reserve plant diaspores in case of experiencing } \\
\text { unfavorable factors; mineral absorption system; } \\
\text { assimilation system; organic absorption system }\end{array}$ & + & + \\
\hline
\end{tabular}
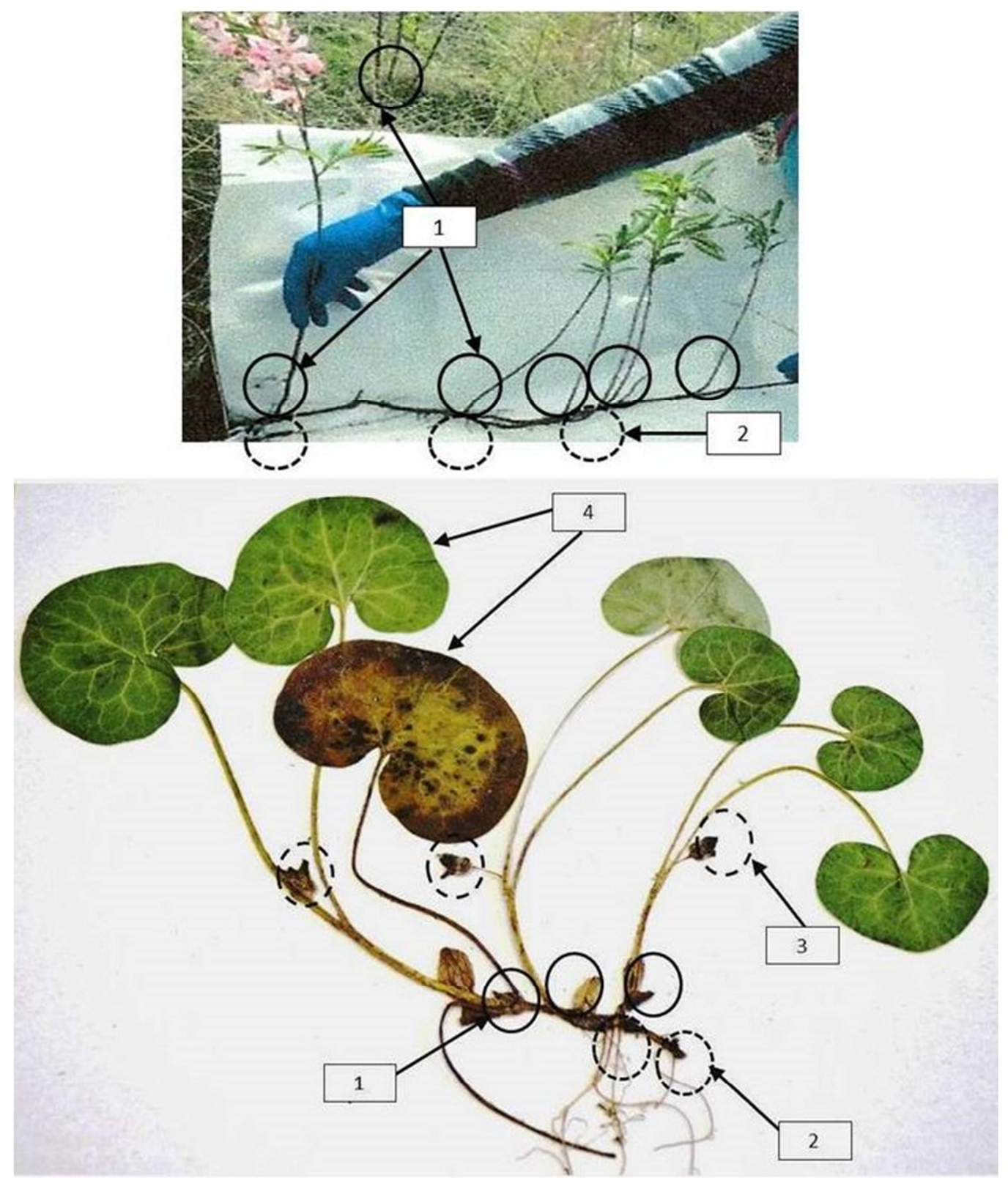

Figure 1. Elements in Polycentric Model of Plant.

Above is Amygdalus nana L. (Rosaceae). The category of life forms "Soboliferous shrub". Author photo R. Aref'eva. Bottom is Asarum europaeum L. (Aristolochiaceae). The category of life forms "Rhizomatous". 1 - Shoot-formation center; 2 - Mineral-nutrition center; 3 - Generation center; 4 . Organic-nutrition center 


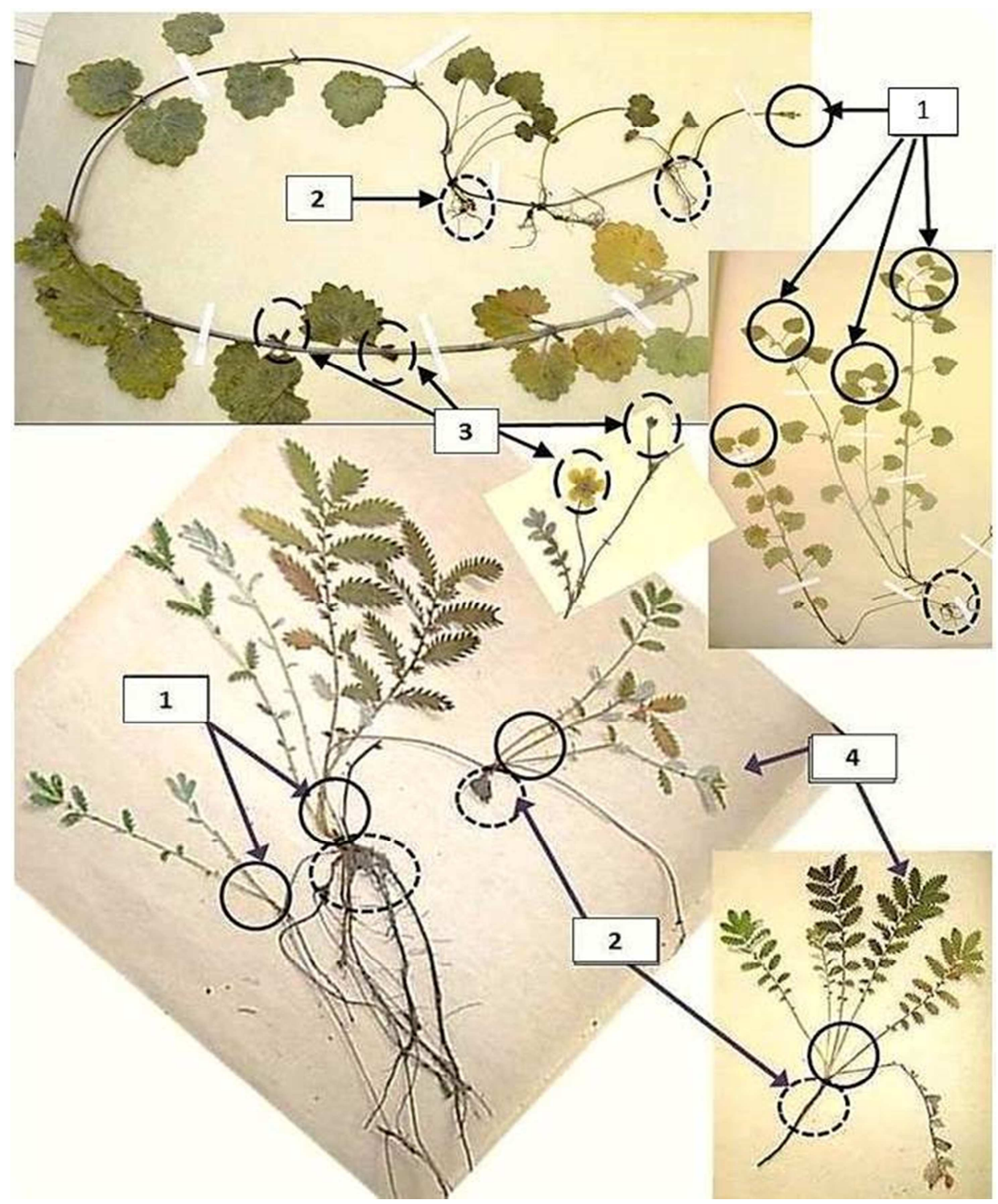

Figure 2. Elements in Polycentric Model of Plant.

Above is Glechoma hederaceae L. (Lamiaceae). The category of life forms "Terrestrial-decumbent”. Bottom is Potentilla anserina L. (Rosaceae). The category of life forms "Terrestrial-stoloniferous". 1 - Shoot-formation center; 2 - Mineral-nutrition center; 3 - Generation center; 4 - Organic-nutrition center

Table 3. Name of Morph-functional groups and their functional role in Population System of Plant from the category of life forms "Terrestrial-stoloniferous".

\begin{tabular}{lllll}
\hline Name & Symbol & Elements on Polycentric Model of Plant & Functional role \\
\hline $\begin{array}{l}\text { Monocentric vegetative } \\
\text { Polycentric vegetative }\end{array}$ & $\mathrm{mcv}$ & $\begin{array}{l}\text { Primary Shoot-formation center; Primary Mineral-nutrition center } \\
\text { Primary and Secondary Shoot-formation center; Primary, perhaps } \\
\text { and Secondary Mineral-nutrition center }\end{array}$ & $\begin{array}{l}\text { biomass accumulation } \\
\text { biomass accumulation, vegetative reproduction }\end{array}$ \\
Monocentric generative & $\mathrm{mcg}$ & $\begin{array}{l}\text { Primary Shoot-formation center; Primary Mineral-nutrition } \\
\text { center; Generation center }\end{array}$ & $\begin{array}{l}\text { biomass accumulation, generative reproduction } \\
\text { and Secondary Mineral-nutrition center; Generation center }\end{array}$ & $\begin{array}{l}\text { biomass accumulation, vegetative } \\
\text { reproduction, generative reproduction }\end{array}$ \\
\hline
\end{tabular}

The density of the individual disposition of plant was so high that the formed type of plant community "A. nana bush". Geographical area of the study Bugulma-Belebey Upland in the East European Plain to the west of the Ural Mountains $\left(54^{\circ} 55^{\prime} \mathrm{N} ; 52^{\circ} 25^{\prime} \mathrm{E}\right)$. Botanical Region: Eastern for the Kama. Administrative binding: Almetyevsk municipal District, Tatarstan Republic, Russia.

Consider A. nana hypothetical lifecycle in Concept
"Polycentric Model of Plant". Growth and development of the plant that develops from the seed for several years is due to the work of exogenous (terminal and lateral) and endogenous (lateral) buds. These processes are accompanied by the growth of orthotropic, lignified shoot with long interstices and mixed-type root system. The work of the side bud, localized on the wood shoot, promotes the formation of the crown.

Thus, the Primary shoot-formation center having 
Organic-nutrition centers in the crown is formed, as well as the Primary mineral-nutrition center. In the root system, an elongated lignified horizontal root differentiates. This root is capable of forming the adventitious bud. The process of bud development localized in the root promotes the formation of underground orthotropic shoot with exogenous and endogenous buds and the formation of suction roots. Thus, Secondary shoot-formation center and Secondary mineral-nutrition center are formed.

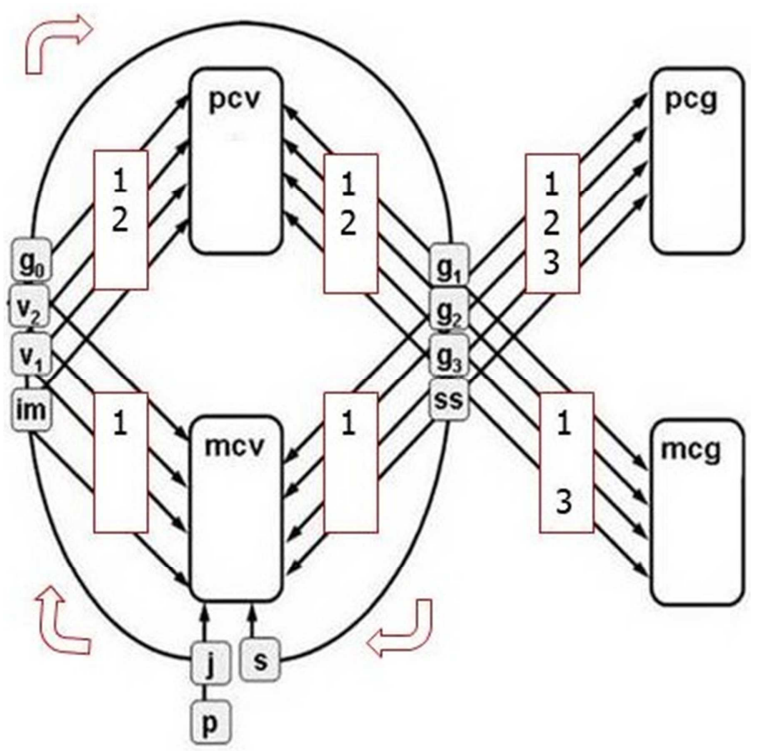

Figure 3. Hypothetical Lifecycle of Plant from the category of life forms "Terrestrial-stoloniferoum”.

"p, j, im, $v_{1}, v_{2}, g_{0}, g_{1}, g_{2}, g_{3}, s s, s "$ - ontogenetic group [29, 30]; "mcv, pcv, mcg, pcg" - Morph-functional group; 1 - Organic-nutrition center; 2 Stolon; 3 - Generation center

Further growth of the development of Secondary shoot-formation center and Secondary mineral-nutrition center occurs by analogy with the development of Primary that centers. As the physiological aging of the horizontal root communication areas or as result of the mechanical action, the vegetative reproduction process takes place.

The buds localized in $A$. nana crown are differentiated according to the function in 3 types. Type 1. It has protective scales. The bud provides the growth of a shoot with elongated interstices, which subsequently lignifies and forms skeletal branches in the crown. Type 2. It has or has not protective scales. The bud provides growth of an annual shoot with short internodes, that are not capable of lignify and that vegetate only one growing season. Type 3 . It has protective scales. It provides an increase in shoots with shortened internodes and formation of Generation center.

Buds of all types provide growth and development of Organic-nutrition centers. These are simple leaves, oval in outline (0.9-7.2 $\mathrm{cm}$ along the central vein). Over time, the crown can reach a height of $2 \mathrm{~m}$. During the growing season the bud develops, which in the next growing season ensures the formation of a one-year shoot with short internodes and the formation of Generation center. Generation center undergoes two phases of development: flowering (pink bisexual flower); fruiting (dry single-seeded drupe). Pollinating the plant is with the help of agents (insects, wind). There is also self-pollination. The flowering process occurs simultaneously with the process of leaf opening. Vegetative season in the research area are May-October. Phase flowering in May, the phase of fruiting in the time range of June-August. In natural habitats, the number of Generation centers in the flowering phase far exceeds those in the fruiting phase. Part of the reason for this is the exogenous factor (the lack of macro and microelements in the soil). Experience with plant species from the life forms category "Vegetative-mobile" suggests that and the endogenous factor in many ways determines the strategy of population system self-development in the territory [1-3, 5 , $6,8]$.

The peculiarity of plant development contributes to the formation of polycentric system in which Primary and Secondary shoot-formation and mineral-nutrition centers are removed from each other in space, but are physiologically related to each other by system of horizontal roots (Figure 1). Within its boundaries are problematic to distinguish Primary or Secondary shoot-formation centers.

What exactly is the bush thicket of one polycentric system with Primary and Secondary shoot-formation and mineral-nutrition centers, or are the products of vegetative reproduction of one or several polycentric systems? To diagnose the habitat, the answer to the question is not significant. The state of the above-ground elements of $A$. nana polycentric system will tell the researcher much more about the state of the plant population system. Therefore, it is advisable to determine the stage in the lifecycle of a part of a polycentric system formed by one Shoot-formation and Mineral nutrition centers.

I propose structuring Hypothetical Lifecycle of Plant from the category of life forms "Shrub" into a series of 7 stages (Table 4).

Table 5 provides Diagnostic Key for determining the stage in Hypothetical Lifecycle of Plant according to two main elements: the age group and phenological phase (vegetation or vegetation and generation). The key is universal and suitable for plants of different species from the category of life forms "Shrub". Figure 4 illustrates those 7 stages on the example of A. nana control samples.

The proposed Diagnostic Key for determining the stages in Hypothetical Lifecycle of Plant from the category of life forms "Shrub" has the prospect of widespread use in the practice of diagnosing the state of the habitat. The methodological approaches used in the process of structuring Hypothetical Lifecycle of Plant from the category of life forms "Shrub" into a row of stages, and in the process of determining each of these stages, it is advisable to recommend for use in similar developments in relation to plants from the more general category "Vegetative-mobile".

The simplicity of determining the stage of development in the hypothetical lifecycle of a plant minimizes the subjective evaluation and has a perspective for: 1) to organize research with the participation of gifted children; 2) to generalize of the 
facts that were obtained and will be obtained in the course of studies with plants in the framework of various methodological approaches; 3 ) to develop of measures for the rational use and conservation of plant resources.

\section{Concept "Polycentric Model of Plant" and Principles of Plants Population-based Research}

Population-based research is a process of gradual cognition of the features of plant growth and development in a specific habitat. To increase the effectiveness of population-based research, it is expedient to adhere to 4 fundamental principles.

Principle 1. Description of Hypothetical Lifecycle of the plant in concept "Polycentric Model of Plant" from the germination of a seed or spore to the complete withering away of the body plant.

Principle 2. Description of deviations from Hypothetical Lifecycle of the plant based on the morphometric evaluation of plant parameters in different population systems.

Principle 3. Statistical analysis of the plant population system based on quantitative indicators characterizing one or another Center in structure individuals of the plant.

Principle 4. Forecast near term development of plants in the population system of one or several species.

Below are the points of population-based research of plants to which it is expedient to attract gifted children.

Point 1. It is collecting material. There are two options of collection of material in the plant community, in the ecotone, in the experimental plot: 1) take all plants in a row on the trial plot, for example 1 sq.m (for grass land and aquatic plants); take all plants in a row of at least 50 individuals; take all plants in a row of at least 10 individuals that are located according to a certain pattern at 5 points; 2) take morphometric of indicators control individuals plant that grow on the trial plot and continue their growth there after their inspection.

Point 2. It is diary of observations. Create a Polycentric Model of Plant for each species. Measure the most significant for the purpose of the research morphometric indicators in plants within the sample for detailed characterization of the model elements.

Point 3. It is structuring the population system by groups of individuals. There are different methodological approaches to the structuring of the population system by: 1) morph-functional groups; 2) morphological groups; 3) ontogenetic groups; 4) vitality groups [31]. Determine the quantity of individuals in each structural group.

Point 4. It is preparation of experimental data for analysis, taking into account the structuring of the plant population system. Create the spectra characterizing this or that structure for each population system, for each material collection date. Create variation-rows for each of the morphometric indicators characterizing one or another center in Polycentric Model of the plant: for each element of the population system; for each habitat; for each material collection date. Construct a distribution curve for 5 ranks for each variation row.

Point 5. It is conducting statistical and mathematical data processing. Here it is necessary to perform a number of actions: 1) calculate the parameters for descriptive statistics; 2) calculate Coefficient of variation for each indicator; 3) calculate the criterion for identifying similarities or differences between the same indicators in different variation-rows. It can be $R$. Fisher Criterion (paired two-sample $F$-test for the dispersion (you can use other tests). Assess the reliability of $F$-test at different significance levels; 4) calculate Criterion of K. Pearson (Chi-Squared test) for each pair of distribution curves and for each pair of spectra. Assess the reliability of the similarity of distributions at different levels of significance; 5) calculate Pearson correlation coefficient for each pair of indicators in the compared options. Assess the reliability of this coefficient at different significance levels; 6) construct the dot diagrams of the dependence of one indicator on the other " $y$ " on " $x$ ". Find the most reliable approximation (trend line).

Point 6. It is presentation of the results. Create tables, matrix tables and gather diagrams and photos in to figures. In the matrix tables, mark the level of reliability of the criteria with symbols: "*, **, ***, ****" in accordance with a significance level of " 90 ; 95; 99; 99.9\%".

Point 7. It is preparation for discussion. Choose sources by topic and quotes for discussion of the research.

Table 4. Stages in Hypothetical Lifecycle of Plant from the category life forms "Shrub".

\begin{tabular}{|c|c|c|c|c|c|c|c|}
\hline $\begin{array}{l}\text { Stages in Hypothetical } \\
\text { Lifecycle }\end{array}$ & $\mathbf{I}_{\mathbf{V}}$ & $\mathbf{I I}_{\mathbf{v}}$ & $\mathbf{I I}_{\mathrm{VG}}$ & $\mathrm{III}_{\mathrm{V}}$ & III $_{\mathrm{VG}}$ & $I V_{V}$ & $I V_{V G}$ \\
\hline Age group & I & II & & III & & IV & \\
\hline Phenological phase & vegetation & vegetation & vegetation, generation & vegetation & vegetation, generation & vegetation & $\begin{array}{l}\text { vegetation, } \\
\text { generation }\end{array}$ \\
\hline
\end{tabular}

Table 5. Diagnostic Key for determining the stage in Hypothetical Lifecycle of Plant from the category life forms "Shrub".

\begin{tabular}{|c|c|c|c|c|c|c|c|}
\hline \multirow{2}{*}{ Features in Morphological Structure of Plant } & \multicolumn{7}{|c|}{ Stage in Hypothetical Lifecycle } \\
\hline & $\mathbf{I}_{V}$ & $\mathbf{I I}_{V}$ & $\mathbf{I I}_{V G}$ & III $_{V}$ & III $_{V G}$ & $\mathbf{I V} \mathbf{V}_{V}$ & $\mathbf{I V} \mathbf{V}_{V G}$ \\
\hline Generation center in the flowering or fruiting phase & - & - & + & - & + & - & + \\
\hline $\begin{array}{l}\text { Percentage of lignified branches in the corona with Organic-nutrition } \\
\text { center, } \%\end{array}$ & 100 & \multicolumn{2}{|c|}{$\begin{array}{l}60-100 \text { more than } \\
\text { half }\end{array}$} & \multicolumn{2}{|c|}{ 40-60 about half } & \multicolumn{2}{|c|}{$\begin{array}{l}0.1-40 \text { less than } \\
\text { half }\end{array}$} \\
\hline Shoot formed by the bud of crown in the year of observation & + & + & + & + & + & + & + \\
\hline Shoot formed by the bud of root or rhizome until the year of observation & - & + & + & + & + & + & + \\
\hline Shoot formed by the bud of root or rhizome in the year of observation & + & $-1+$ & $-1+$ & $-1+$ & $-1+$ & - & - \\
\hline
\end{tabular}




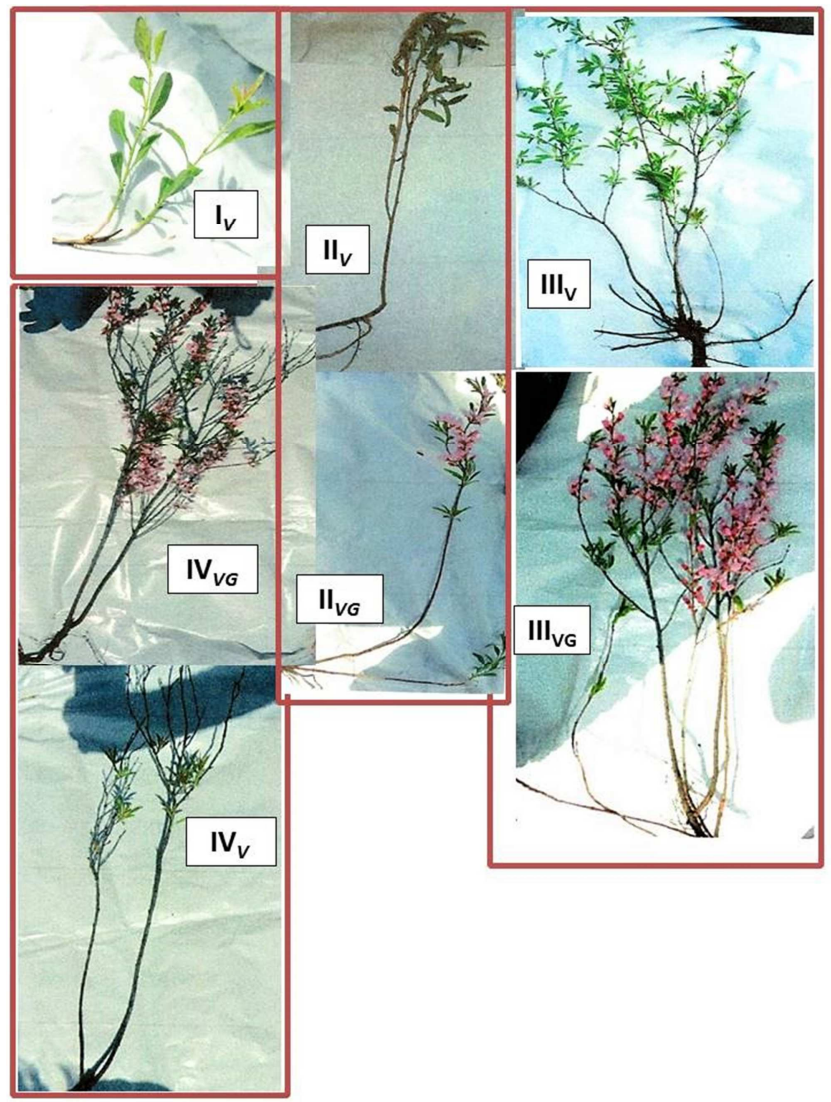

Figure 4. Samples Amygdalus nana, illustrating the stages in Hypothetical Lifecycle of Plant from the category of life forms "Shrub". Point of growth: Almetyevsk District, Tatarstan Republic, Russia. Photo May, 2012. Authors Photo: N. Tasheva, R. Arefeva.

Point 8. It is registration of the bibliographic list. Make a list of sources involved to discuss the results, according to the rules.

The most difficult part of such a population-based research of plants (selection of test plots and description of environmental conditions; selection of objects; description of the hypothetical life cycle of a plant and deviations from it; environmental diagnostics) can only be solved by an experienced researcher. Therefore, at these stages of the study, gifted children should be involved only as observers.

A number of my publications [1, 2, 3, 6-11, 13, 14, 18, 2125 ] present the results of a population-based research with different plant species conducted using this algorithm (most of the publications are presented in Russian).

\section{Concept "Polycentric Model of Plant" - Tool for Diagnosing the Stage of Digression Steppe Vegetation}

Since 70-ies of XX century, geobotanists started talking about pasture digression steppe landscape due to the decrease in the area covered by vegetation, giving high yields of forage plants. This situation arose as a result of an increase in the anthropogenic load in the form of an unlimited increase in the number of livestock and unregulated grazing in regions with a tradition of nomadic cattle breeding. Revision of the steppe is carried out regularly in such regions and currently geobotanists try to differentiate vegetation at different stages of digression. However, joint work with Mongolian geobotanists has shown that the definition of one or another stage of digression is intuitively conducted, since clear criteria are not described in any of the grazing digression scales they use. Intuitive approach is largely justified, and gives positive results. Based on the results of research conducted by such methods, scientists develop measures for the rational use of vegetation and justify the regimes of the annual cycle of pasture exploitation. But, the scientific approach presupposes mathematically verified data, which does not depend on the features of the perception of vegetation through the eyes of a scientist.

It so happened that I was suddenly faced with the problem of pasture digression steppe vegetation in Mongolia. Tandem work with a graduate student from Mongolia [25, 27] and my personal observations of various pastures in the steppes of Central Mongolia (including North Gobi) in the summer of 2016, within the framework of the International Complex Expedition, organized by the Institute of Geography and Ecology at Mongolian Academy of Sciences, pushed me to reflections [19, 21-24]. The result of these reflections I bring to your attention.

The concept steppe is ambiguous. I will focus on the fact that the steppe is a type of treeless vegetation formed mainly by xerophilous plants from different categories of life forms. In the normally developing steppe, "Perennial" dominate, forming a sod (Stipa krylovii Roshev., Cleistogenes squarrosa (Trin.) Keng, Leymus chinensis (Trin.) Tzvelev., Agropyron cristatum (L.) P. B., Koeleria macrantha (Ledeb.) Schult. (Poaceae); Potentilla bifurca L., (Rosaceae); Aster alpinus L. (Asteraceae); Allium mongolicum Regel (Alliaceae), Urtica cannabina L. (Urticaceae) and etc.). There are "Annual" and "Biennial", "Dwarf semifrutex" and "Semifrutex" (Artemisia adamsii Besser, Artemisia frigida Willd (Asteraceae) and etc.). There can grow "Dwarf shrub" and "Shrub" runty with deep and powerful roots (Ephedra sinica Stapf. (Ephedraceae) and etc.). All of these representatives form a grass-shrubbery tier. As part of this tier, the projective cover by plant species changes depending on the environment.

In the steppe, "Shrub" having well-developed crown (Caragana microphylla Lam., Caragana ungei Ledeb. (Fabaceae), Calligonum aphyllum (Pall.) Guerke (Polygonaceae), Amygdalus nana L. (Rosaceae) and etc.) can grow. Separately standing "Tree" can also grow in the steppe landscape. All of these representatives form a shrub tier and their crowns are located over the representatives of the grass-shrubbery tier. If the crown projection exceeds $60 \%$, then I can say that the type of steppe vegetation has been replaced by the type of bush or light forest vegetation. If the percentage of plants capable of forming a sod in the composition of grass-shrubbery tier is less than $10 \%$, then I can say that the type of steppe vegetation has been replaced by 
the type of desert vegetation. However, how can this share be assessed? This question made me solve a number of tasks: 1) to develop a universal diagnostic key for identifying the main elements of vegetation; 2) to develop a formula for determining the coefficient of digression steppe vegetation based on vegetation elements.

In order to be able to isolate phyto-IDs scale digression steppe vegetation it was necessary to consider two main geobotanical indicators: 1) total crowns projection of shrubs and trees; 2) percentage of perennial plants capable of forming sod in the composition of the grass-shrubbery tier.

To identify the latter, a universal scale of Vegetation Elements was developed (Table 6). Thanks to this scale, each biological species of the plant as part of the vegetation had its own defined place and it became possible to determine the percentage of coverage of one of the elements of the vegetation (in particular, including species capable of forming sod) in the rest of the plant community.

In Table 6 shows Diagnostic Key for determining Vegetation Element. Such elements are 5. There unite plants from different categories of life forms as follows: I - "Annual" and "Biennial"; II - "Perennial" capable of forming a sod; III - plants capable of forming something out of a row: stolon, long rhizome, creeper or decumbent shoot, creeper root ("Perennial", "Semifrutex", "Dwarf semifrutex", "Dwarf shrub" and "Shrub" runty not capable of forming a crown); IV - "Shrub" capable of forming a crown and "Tree" capable of forming a creeping-rooted; V - "Tree" not capable of forming a creeping-rooted.

Using this diagnostic key on the material of the standard geobotanical description of plant community, it is possible to conduct a mathematically accurate calculation of Coefficient Digression of Steppe Vegetation $C d s v, \%$. To do this, it is necessary to determine the projective cover of each plant species on 5-point radicalized scale, in which points 1, 2, 3, 4, 5 correspond to cover intervals 0-4-16-36-64-100\% [28]. The formula for calculate Coefficient Digression is such that it takes into account the elements of vegetation steppe forming the grass-shrubbery tier:

$$
C s v d=100(\Sigma a / \Sigma(a+b+c)),
$$

were $\Sigma$ - sum of the cover points of plants forming one or another element of vegetation: $a$ - correspond to the element II; $b$ and $c$-correspond to elements I and III.

In Table 7 shows the Scale of Digression Steppe Vegetation and its Phyto-IDs. Logical thinking and mathematical calculation led me to what is most appropriate to allocate 5 stages of digression steppe. The boundaries of the digression stages are mathematically determined using Coefficient Digression and the crowns projection of shrubs.

\section{Experimental Results with Potentilla anserina L. (Rosaceae) in Concept "Polycentric Model of Plant"}

\subsection{Introduction}

The field diary of botanist is a valuable document, since it stores information about the life of plants in different time periods. This is the basis for monitoring plant systems at various levels of organization. The methodological apparatus of scientific research is being modernized and the information contained in the field diary is given the opportunity to be interpreted in a new way.

Let us turn to the experimental data from Potentilla anserina, which were collected in 1996-1998 during my postgraduate studies at the Department of Botany at Kazan State University at a bio-station. Administrative link:

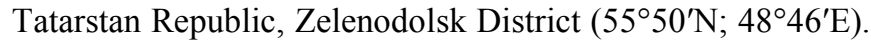
The experimental results were presented in a series of publications [1, 3-6]. Later, during the reform of higher education in Russia, the status of the University and its domestic policy changed: the department of botany was disbanded, and the bio-station was closed. The experimental data will be revised in Concept "Polycentric Model of Plant".

Table 6. Diagnostic Key for determining Vegetation Element.

\begin{tabular}{|c|c|c|c|c|c|}
\hline \multirow{2}{*}{ Indicators characterizing maximally developed hypothetical individuals of the plant species } & \multicolumn{5}{|c|}{ Vegetation Element } \\
\hline & $\mathbf{I}$ & II & III & IV & $\mathbf{V}$ \\
\hline Quantity of Shoot-formation centers, pcs & 1 & $1>$ & $1>$ & $1>$ & 1 \\
\hline Quantity of Mineral-nutrition centers, pcs & 1 & $1 \geq$ & $1>$ & $1>$ & 1 \\
\hline Shoot formed by the bud of the crown & - & - & - & + & + \\
\hline Length of the connection portion on root, rhizome or creeper shoot between of Shoot-formation centers, $\mathrm{cm}$ & - & $\geq 0.4$ & $0.4>$ & $0.4>$ & - \\
\hline
\end{tabular}

Table 7. Scale of Digression Steppe Vegetation and its Phyto-IDs.

\begin{tabular}{lll}
\hline Point on Scale & Cdsv, $\%$ & Crown projection of Vegetation Elements (IV+V), \% \\
\hline Normal steppe & $60 \geq$ & $\geq 10$ \\
The stage of digression I & $50>60$ & $10>20$ \\
The stage of digression II & $40>50$ & $20>30$ \\
The stage of digression III & $30>40$ & $30>40$ \\
The stage of digression IV & $20>30$ & $40>50$ \\
The stage of digression V & $10>20$ & $50>60$ \\
Degraded steppe & $\geq 10$ (desert) & $60 \geq$ (bush or light forest) \\
\hline
\end{tabular}

Purpose of the study was to identify $P$. anserina population responses to seasonal changes in climatic factor.
Tasks: 1. Present the change in the statistical parameters of indicators characterizing the growth and development of the 
plant (in concept "Polycentric Model of Plant") in plantings of the different individual disposition during the vegetative season; 2. Determine integral indicators characterizing the seasonal change in the climatic factor (total average daily temperature, total longitude of daylight hours, total rainfall) in the study area according to climatic reports for the periods between control observations of the plant; 3 . Assess the similarity and difference in the plant seasonal rhythm in plantings of the different individual disposition; 4. Describe the responses of plant population system to changes in climatic factor; 5. Identify differences and similarities in the seasonal rhythm of the plant in plantings of the different individual disposition; 6. Identify growth indicators of a model plant population system developing in experimental plots, and its morph-functional specter in the second and third year of observations.

\subsection{Research Methods}

On May 30, 1996, P. anserina young individuals that did not form stolon and generation center were selected from the natural plant community "P. anserina + Poa аппиа L. + Trifolium repens L.". These were planted in freshly excavated sod-podzolic medium loamy soil to 12 stationary plots in the open air with an area of $1 \times 1$ sq.m each and were abundantly watered. Further planting care consisted only in the removal of plants of other species. There were 3 planting options in terms the density of individual disposition at plots: 1,5 and 9 ind./sq.m (Figure 5). Each option had 4 replicates. In the process of observing plants every 2 weeks from June to October, the indicators characterizing the polycentric system were taken into account: 1) quantity of secondary shoot-formation centers; 2) quantity of secondary mineral-nutrition centers; 3) quantity of generation centers, 4) quantity of stolon.

The experiment data was statistically processed in the Microsoft Excel editor using "Analysis Package: Descriptive Statistics". Climate data are taken from Kazan University Observatory reports. Graphs of the dependence of plant indicators on climatic indicators are constructed using the "Scatter diagram" with the selection of the most reliable approximation. The diagrams show the trend lines, the equation of the dependence of " $y$ " on " $x$ " and the confidence coefficient $R^{2}$. In Table 8 presents the following parameters: $M$ - arithmetic mean, $\Delta$ - confidence interval (it is also that the reliability level) at a significance level of $90 \%, C v, \%$ Coefficient of variation, $n$ - sample size.

\subsection{Results}

The growing season of 1996 was not distinguished by a particularly high temperature background and sharp jumps in temperature. The maximum daily average temperature was $27.9^{\circ} \mathrm{C}$. The duration of periods without precipitation varied from 1 to 17 days. Precipitation was in the form of heavy rains or prolonged (up to 7 days) rains. But, more often it was 2-day light rains.

The average daily temperatures between the periods of control observations of plants in 1996 changed as follows: $19.03,22.07,19.46,17.76,17.72,9.09^{\circ} \mathrm{C}$. The average daily precipitation between the periods of control observations of plants changed as follows: $1.15,0.69,0.91,0.29,0.48,1.38$ $\mathrm{mm}$.

Planted $P$. anserina individuals quickly adapted to the new environment. In mid-June, the beginning of the formation of stolon and secondary shoot-formation centers was observed. Subsequently, these processes accelerated and continued until the end of September. In the first decade of July, the beginning of the formation of secondary mineral-nutrition centers was observed. In the future, this process accelerated. It continued until the end of September and later, until stable negative temperatures were established.

The processes of formation of organic-nutrition centers, generation centers and their metamorphoses was observed during the growing season in connection with the development of secondary shoot-formation centers and / or in connection with the branching of a rosette shoot in the primary shoot-formation center.

The flowering process began to be observed from mid-June and continued until the end of September and later. The fruiting process began to be observed from mid-July and continued until the end of September and later. The greatest quantity of generation center in the flowering phase was noted from July 8 to August 9, and in the fruiting phase from August 9 to September 9. That is, the duration of the metamorphosis of the generation center associated with a change in the functions of quantity of generation center the plant was about 1 month. During this period, the synchronous development of sexual structures and perianth occurred in the generation center, and subsequently the synchronous development of the seed and fruit.

In the second half of August, the drying process of individual internodes was observed in the extension zone on the stolon. This contributed to the formation of clones. In some cases, the drying process was so rapid that it contributed to the transition of the individual to a state of physiological rest. So, instead of 36 planted individuals in the option 9 ind./sq.m, after August 8, 33 actively functioning individuals remained. Fragments of stolon dried up in some polycentric systems, together with secondary centers of shoot-formation, sometimes with secondary mineral-nutrition centers. Clones were isolated from the parent, but were chains of equivalent centers of shoot-formation and mineral-nutrition. There differentiation into primary and secondary centers disappeared.

The climatic factor in the growing season causes a particular response from the polycentric system (Figures 7-9).

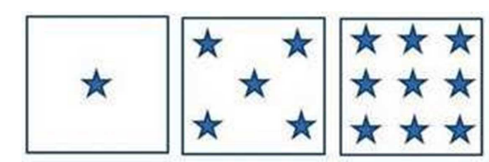

Figure 5. Scheme of the individual disposition at the time of planting at experimental plots on May 30, 1996.

For example, the maximum quantity of secondary 
shoot-formation centers is observed with the sum of temperatures and the sum of daylight hours approaching the minimum, but with the amount of precipitation approaching the minimum or maximum. The maximum quantity of generation centers and secondary mineral-nutrition centers is observed with the sum of temperatures and the sum of daylight hours approaching the minimum, and with the sum of precipitation close to the maximum. Those, in the autumn period with cool weather and periodic not too heavy rains, the polycentric system of the plant is able to support the development the maximum quantity of shoot-formation centers and generation centers due to the development the maximum quantity of mineral-nutrition centers. This feature of the plant becomes the reason that metamorphosis at some centers of generation does not complete in the autumn period. This happens the next growing season. Therefore, it is no coincidence that individuals with last year's fruits are found in $P$. anserina population system. By the way, the same feature was revealed in another biological species of the plant Potentilla astragalifolia Bunge, which is very similar in morphological characteristics to P. anserina [23, 24].

The density of individual distribution $P$. anserina determines: 1) the growth rate of a single polycentric system. It decreases significantly with increasing density from 1 to 9 ind./sq.m (Table 8); 2) the rate of overgrowth of soil herbage. This increases as density increases 1 to 9 ind./sq.m (Figure 6).

As a result of the experiment, it was revealed: 1) P. anserina polycentric system is able to form: 19 pcs stolon, 218 pcs secondary shoot-formation centers and 85 pcs secondary mineral-nutrition centers; 2) at the same time in $P$. anserina polycentric system, generation centers in different phases (bud, flower and fruit) in the quantity of 40 pcs can actively function;
3) on the area of 4 sq.m $P$. anserina at the density of individual disposition 1, 5 and 9 ind./sq.m is able to form: 54, 205 and 289 pcs stolon; 633, 1270 and 1972 pcs secondary shoot-formation centers; 204, 268 and 238 pcs secondary mineral-nutrition centers, respectively; 4) on the area of 4 sq.m $P$. anserina at the density of individual disposition 1, 5 and 9 ind./sq.m, generation centers in the quantity of 71, 404 and 315 pcs can actively function respectively. At the beginning of June of the second year of observations in 1997, the density of individual disposition in $P$. anserina model population system varied in the range of 23-104 ind./sq.m, and the density of individuals forming stolon varied in the range of 15-98 ind./sq.m respectively. Some individuals were representatives of the "Polycentric vegetative" group, not because of the formation of new stolon, but due to the preservation of last year's stolon. Such individuals were underdeveloped and their assimilating organs dried out. Until the end of summer, the density of individual distribution in the model population system changed. The following processes occurred: 1) in some individuals, the assimilating organs dried out, and these passed into the phase of physiological rest; 2) seeds germinated, but this was extremely rare; 3) in individuals who successfully survived the phase of physiological rest, assimilating organs were formed.

Plots $\mathrm{N} 4$ and N 8 having contrasting, but not high density of individual disposition were selected by me to collect control indicators (Table 9). In conditions of the lower density, the polycentric system at the earlier stages of development (until July 20) formed a larger quantity of secondary centers of shoot formation, and later a larger quantity of secondary mineral-nutrition centers. However, the polycentric system

Table 8. Potentilla anserina polycentric system: seasonal dynamics of metric indicators in the different of individual disposition. Data 1996.

\begin{tabular}{|c|c|c|c|c|}
\hline \multirow[t]{2}{*}{ Quantity, pcs: } & \multirow[t]{2}{*}{ Date } & \multirow{2}{*}{$\begin{array}{l}1 \text { ind./sq.m }(n=4) \\
M \pm \Delta ; C v, \% ; \operatorname{Lim}\end{array}$} & \multirow{2}{*}{$\begin{array}{l}5 \text { ind./sq.m }(n=20) \\
M \pm \Delta ; C v, \% ; \operatorname{Lim}\end{array}$} & \multirow{2}{*}{$\begin{array}{l}9 \text { ind./sq.m }(n=36, \text { but } \\
\text { since August } 25 n=33) \\
M \pm \Delta ; C v, \% ; \operatorname{Lim}\end{array}$} \\
\hline & & & & \\
\hline \multirow[t]{6}{*}{ Stolon } & July 8 & $5.5 \pm 2.0 ; 31 ; 4-8$ & $3.55 \pm 0.5 ; 70 ; 0-7$ & $2.4 \pm 0.62 ; 92 ; 0-8$ \\
\hline & July 26 & $8.25 \pm 1.1 ; 11 ; 7-9$ & $7 \pm 0.72 ; 26 ; 1-10$ & $5.55 \pm 0.7 ; 44 ; 0-10$ \\
\hline & August 9 & $11 \pm 1.2 ; 25 ; 9-15$ & $9.55 \pm 1.01 ; 27 ; 5-15$ & $7.6 \pm 0.71 ; 33 ; 2-12$ \\
\hline & August 25 & $11.25 \pm 2.6 ; 20 ; 9-14$ & $9.8 \pm 1.2 ; 18 ; 5-16$ & $8.4 \pm 0.85 ; 34 ; 2-15$ \\
\hline & September 9 & $12.75 \pm 4.5 ; 29 ; 9-18$ & $10.25 \pm 1.3 ; 33 ; 5-16$ & $8.5 \pm 0.85 ; 35 ; 2-13$ \\
\hline & September 25 & $13.5 \pm 4.8 ; 39 ; 9-19$ & $9.75 \pm 1.4 ; 37 ; 4-18$ & $8.7 \pm 0.97 ; 38 ; 1-15$ \\
\hline \multirow[t]{6}{*}{ Secondary shoot-formation centers } & July 8 & $15 \pm 7.6: 31 ; 7-22$ & $8.7 \pm 3.2 ; 69 ; 0-31$ & $6 \pm 2.3 ; 89 ; 0-8$ \\
\hline & July 26 & $43 \pm 14 ; 71 ; 27-53$ & $28.5 \pm 7.4 ; 67 ; 4-74$ & $19 \pm 3.8 ; 67 ; 0-52$ \\
\hline & August 9 & $98 \pm 44 ; 38 ; 65-151$ & $51 \pm 9.7 ; 27 ; 12-109$ & $40 \pm 6 ; 52 ; 6-87$ \\
\hline & August 25 & $100 \pm 39 ; 32 ; 57-137$ & $63 \pm 10 ; 41 ; 22-109$ & $54 \pm 6.7 ; 42 ; 3-113$ \\
\hline & September 9 & $138 \pm 65 ; 40 ; 75-189$ & $64 \pm 11 ; 46 ; 14-127$ & $57 \pm 7.4 ; 44 ; 6-115$ \\
\hline & September 25 & $158 \pm 74 ; 47 ; 92-218$ & $64 \pm 13 ; 54 ; 21-143$ & $60 \pm 8.8 ; 47 ; 6-124$ \\
\hline \multirow[t]{6}{*}{ Secondary mineral-nutrition centers } & July 8 & $0.5 \pm 0.5 ; 200 ; 0-1$ & $0.25 \pm 0.21 ; 100 ; 0-2$ & $0.13 \pm 0.11 ; 323 ; 0-2$ \\
\hline & July 26 & $4.2 \pm 1.1 ; 23 ; 3-5$ & $2.4 \pm 1.1 ; 121 ; 0-10$ & $2.7 \pm 1.1 ; 150 ; 0-22$ \\
\hline & August 9 & $16.5+7.1 ; 36 ; 11-25$ & $7.45 \pm 3.0 ; 102 ; 0-29$ & $4.4 \pm 1.3 ; 107 ; 0-18$ \\
\hline & August 25 & $14.5 \pm 7.3 ; 43 ; 8-22$ & $6.4 \pm 2.1 ; 86 ; 0-17$ & $4.4 \pm 1.1 ; 83 ; 0-16$ \\
\hline & September 9 & $15.2 \pm 6.2 ; 34 ; 8-20$ & $6.7 \pm 2.3 ; 88 ; 0-17$ & $4.4 \pm 1.2 ; 88 ; 0-15$ \\
\hline & September 25 & $51 \pm 32 ; 52 ; 27-85$ & $13.4 \pm 3.2 ; 62 ; 3-34$ & $7.2 \pm 1.3 ; 61 ; 1-18$ \\
\hline \multirow[t]{6}{*}{ Generation centers } & July 8 & $5 \pm 3.3 ; 56 ; 3-9$ & $3 \pm 1.19 ; 100 ; 0-9$ & $2.6 \pm 1.3 ; 180 ; 0-25$ \\
\hline & July 26 & $12 \pm 6.4 ; 46 ; 8-20$ & $9.1 \pm 2.6 ; 74 ; 0-20$ & $5.2 \pm 1.4 ; 98 ; 0-20$ \\
\hline & August 9 & $18 \pm 14 ; 65 ; 10-35$ & $14 \pm 2.2 ; 42 ; 2-24$ & $7.8 \pm 1.1 ; 49 ; 1-16$ \\
\hline & August 25 & $17 \pm 14 ; 71 ; 6-34$ & $20 \pm 4.3 ; 56 ; 4-40$ & $9.5 \pm 2.1 ; 75 ; 0-29$ \\
\hline & September 9 & $14 \pm 6.9 ; 43 ; 6-20$ & $15 \pm 3.7 ; 59 ; 2-36$ & $8.4 \pm 2.0 ; 80 ; 0-27$ \\
\hline & September 25 & $11 \pm 6 ; 45 ; 6-18$ & $9.77 \pm 3.4 ; 73 ; 0-39$ & $5.8 \pm 1.7 ; 97 ; 0-25$ \\
\hline
\end{tabular}


did not respond with significant changes in the quantity of generation centers in the difference this density. Of course, all indicators of the polycentric system were significantly lower than in the first year of observations, when the density of individuals did not exceed 9 ind./sq.m.

In the autumn period, processes of separation of secondary mineral-nutrition and shoot-formation centers were observed, which contributed to a significant increase in the density of individual disposition. This became apparent in early June in the third year of observations in 1998 (Table 10). Then the projective cover of the grass stand in some areas was close to $100 \%$. The processes of formation of generation centers and stolon were observed. Most of the generation centers were in the "bud" phase, the rest in the "flower" phase. At plot N 5 (planting option 5 ind./sq.m), a very dense silver-green "carpet" was observed. The role of the pile was performed by openwork leaves. The role of thread is stolon. This "carpet" was very attractive from many points of view. From the point of view of a person interested in growing and / or collecting medicinal raw materials (shoots and roots), this was a fragment of plantings on which a large phytomass was formed. From the point of view of the livestock breeder, this was a fragment of pasture resistant to grazing. From the point of view of the landscape designer, it was a fragment of the lawn resistant to anthropogenic factors. From the point of view of an ecologist, it was a fragment of a territory with a disturbed grass stand, which quickly recovered. From the point of view of the botanist, this was a fragment of the plant community "pure thicket $P$. anserina", on the example of which it is possible to determine the growth and development potential of plants from the category of life forms "Terrestrial-stoloniferous". From my point of view, it was a plant population system with unknown indices of density, phytomass and unknown Morph-functional spectrum.
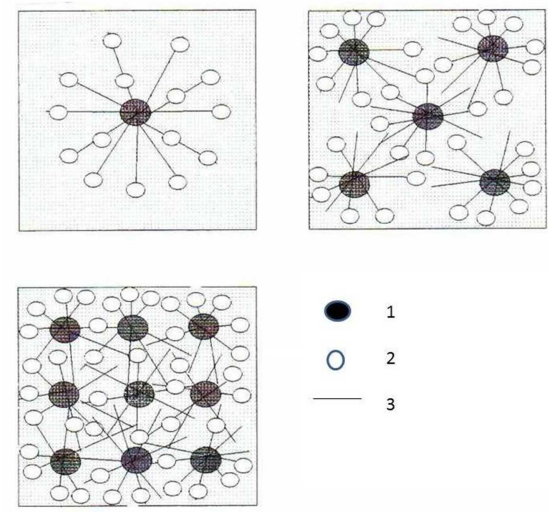

Figure 6. Potentilla anserina polycentric system in the different density of individual disposition: Model scheme of overgrowing experimental plot. Data September 9, 1996.

1- Primary mineral-nutrition center; 2 - Secondary mineral-nutrition center; 3 - Stolon
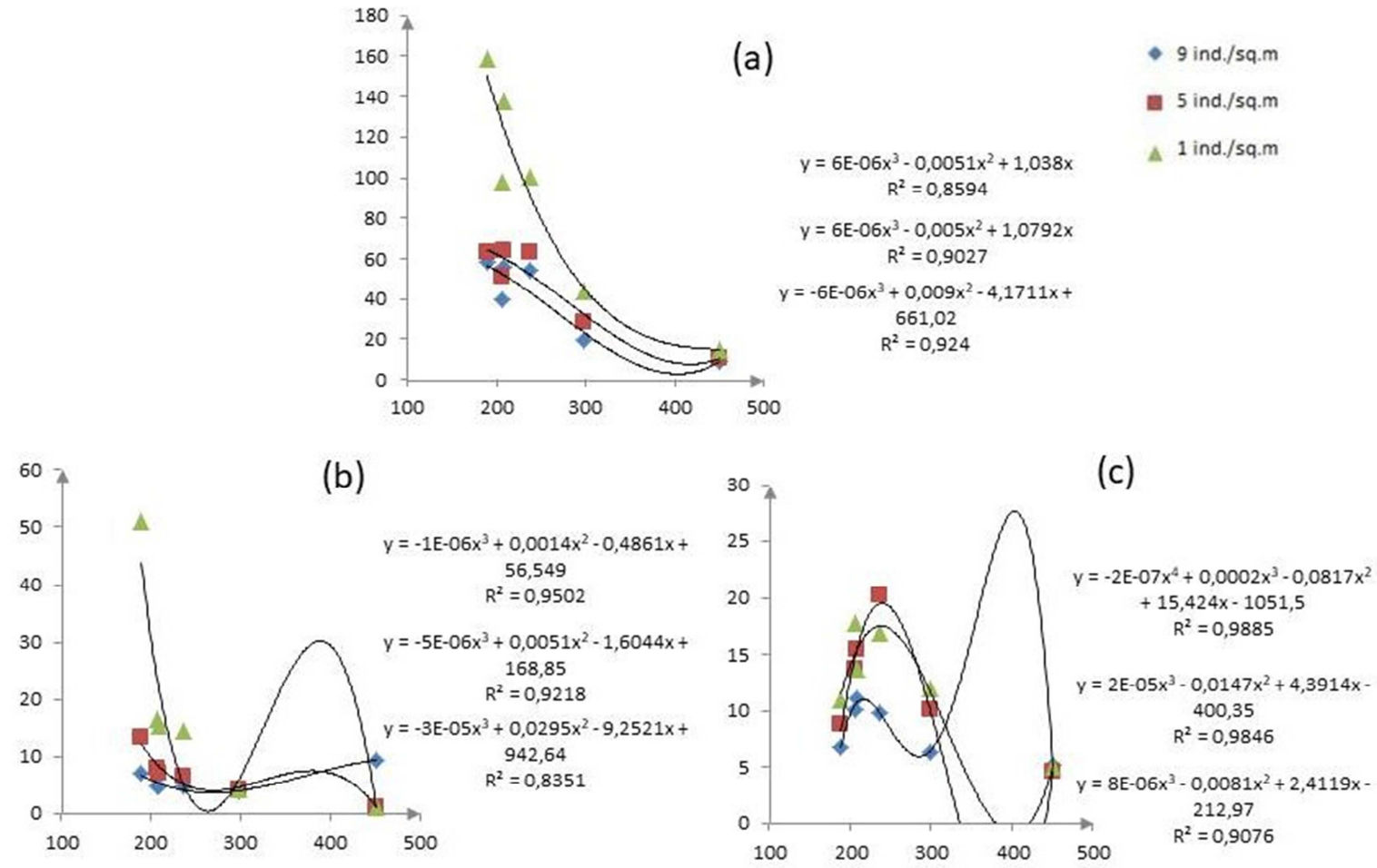

Figure 7. Potentilla anserina polycentric system: Dependence of the average indicator in the different density of individual disposition on the temperatures sum in 1996.

On the ordinate axis (y, pcs) is the indicator average value: quantity of secondary shoot-formation center (a); quantity of secondary mineral-nutrition center (b); quantity of generation center $(\mathrm{c})$. The sample includes individuals with a corresponding indicator. On the abscissa axis $\left(\mathrm{x},{ }^{\circ} \mathrm{C}\right)$ is the daily average temperatures sum for the period between control observations 

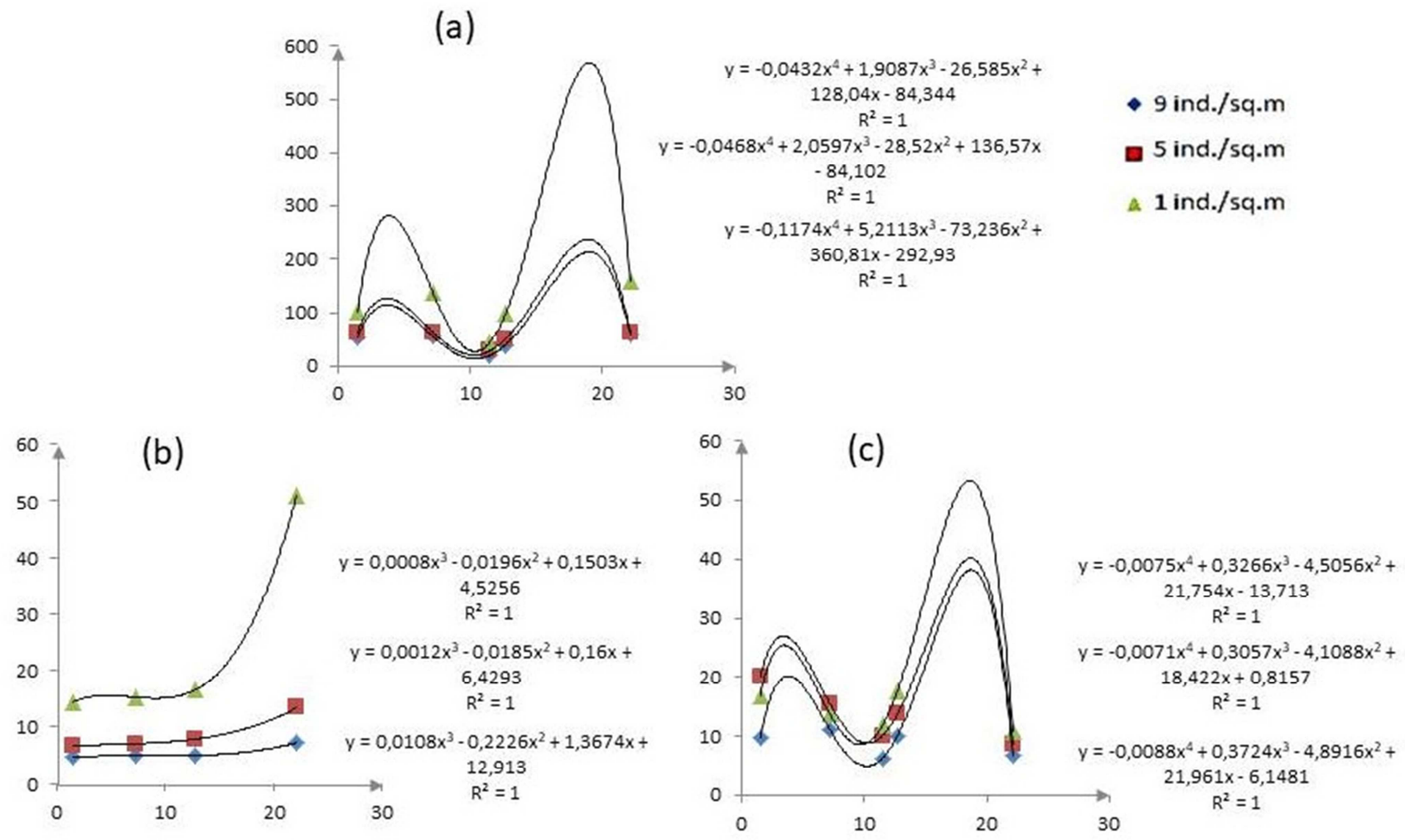

Figure 8. Potentilla anserina polycentric system: Dependence of the average indicator in the different density of individual disposition on the precipitation sum in 1996.

On the ordinate axis (y, pcs) is the indicator average value: quantity of secondary shoot-formation center (a); quantity of secondary mineral-nutrition center (b); quantity of Generation center (c). The sample includes individuals with a corresponding indicator. On the abscissa axis (x, mm) is the precipitation sum that fell during for the period between control observation

The craving for knowledge became an incentive for me to dig out all individuals without exception from Plot N 5. On June 11, individuals were dug up with roots, but root fragments remained in the soil. The same, but later (July 10) was carried out in the remaining 11 plots in which the "carpet" was less dense. At that time, mass flowering was observed in the population system, the Morph-functional spectrum was clearly manifested, a network of stolon covered the soil, and secondary shoot-formation and mineral-nutrition centers were formed. Immediately, the soil in Plot N. 5 was dug to a depth of $20 \mathrm{~cm}$, loosened, and periodically watered until emergence of $P$. anserina. In other areas, the soil was not dug up, but was only watered several times before the emergence of $P$. anserina.

In June and July, weather conditions were favorable for plant growth. The population system was rapidly resuming (Figure 10). At the end of July, of individual distribution in the renewed population system at Plot N 5 was quite high. The processes of flowering and stolon formation were observed. And again, the thirst for knowledge became my incentive to dig out all individuals without exception from site number 5 . On August 1, individuals were dug up with roots, but root fragments remained in the soil. The soil was not dug up, but was only watered several times before the emergence of $P$. anserina.

Examination of individuals dug up at different times and air-dried and analysis of the collected and processed data made it possible to reveal some secrets from the life of the plant (Table 10, 11, Figure 11).

$P$. anserina population system is able to withstand an extremely high density of individual disposition (962 ind./sq.m) and form an above-ground dry living phytomass of 195.38 g/sq.m. In the primary shoot-formation center, the plant forms 1 pcs rosette shoots mainly having 3-4 pcs leaves, but some individuals are able to have more developed and / or branched shoot-formation centers. There, 2-5 pcs rosette shoots formed in the primary shoot-formation center. Thus, in $P$. anserina population system, the leaf density can reach 2886 pcs/sq.m and higher. The maximum length of the leaf blade in the primary shoot-formation center can reach $48 \mathrm{~cm}$, and the length of the peduncle is $33 \mathrm{~cm}$.

In the first decade of June, after a month of active vegetation under conditions of extremely high density of individual disposition, $P$. anserina polycentric system is able to have 3 pcs stolon or 6 pcs generation centers. 335 ind. polycentric systems growing on an area of 1 sq.m are able to form 657 pcs of generation centers, and 184 ind. -215 pcs of stolon (Tables 10, 11). In the population system, both morph-functional spectrum and morphological spectrum are simultaneously manifested, based on the indicator maximum leaf blade length (Figure 11). In morph-functional spectrum the density of "Polycentric vegetative group" can reach 96 
ind./sq.m, and the density of "Polycentric generative group" can reach 89 ind./sq.m.

In the first decade of July, in a population system with the density of individual disposition 295-301 ind./sq.m: 1) $P$. anserina polycentric system is capable of having 4 pcs stolon or 12 pcs generation centers. Other indicators of the density of the population system are able to achieve the following values: the stolon quantity - 288 pcs/sq.m, the length of stolon network - $27.16 \mathrm{~m}$; the secondary shoot-formation centers quantity - 1152 pcs/sq.m; the secondary mineral-nutrition centers quantity -386 pcs/sq.m.

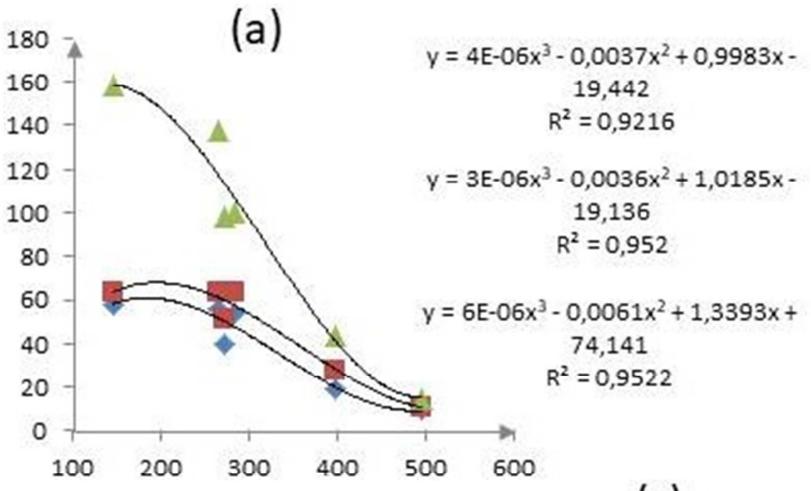

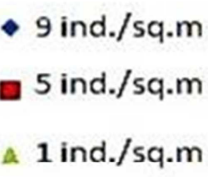

(c)
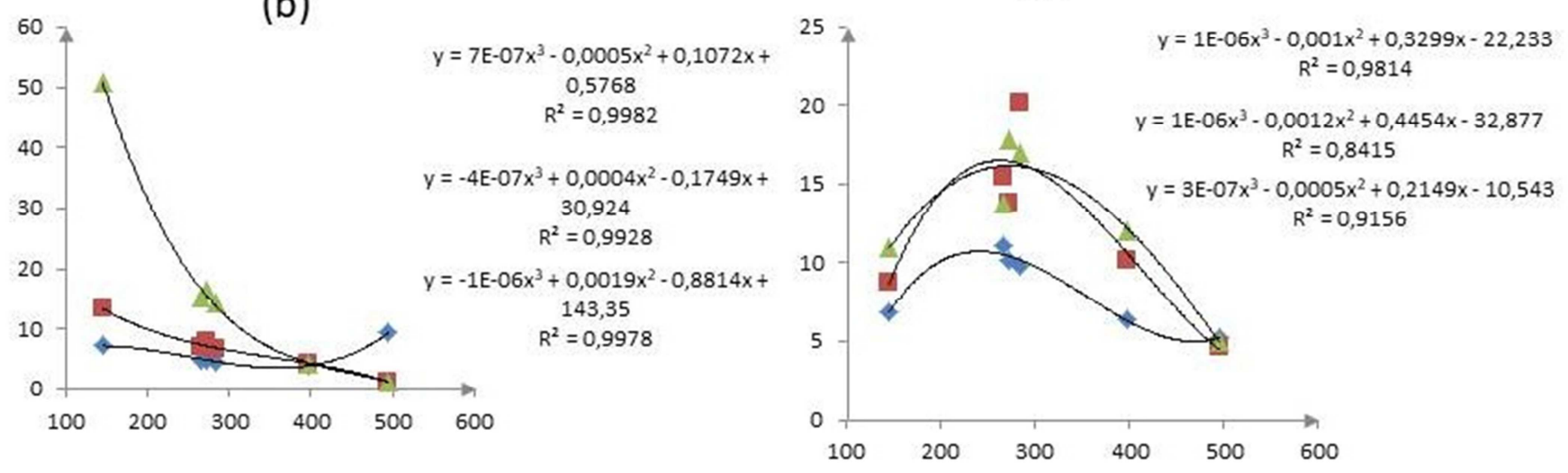

Figure 9. Potentilla anserina polycentric system: Dependence of the average indicator in the different density of individual disposition on the daylight hours sum in 1996.

On the ordinate axis (y, pcs) is the indicator average value: quantity of secondary shoot-formation center (a); quantity of secondary mineral-nutrition center (b); quantity of generation center (c). The sample includes individuals with a corresponding indicator. On the abscissa axis (x, hour) is the daylight hours sum for the period between control observations

Table 9. Potentilla anserina polycentric system: Seasonal dynamic of metric indicators in the different density of individual disposition and F-test to confirm their differences. Data 1997.

\begin{tabular}{|c|c|c|c|c|c|c|c|}
\hline \multirow{2}{*}{ Quantity, pcs: } & \multirow{2}{*}{ Date } & \multirow{2}{*}{$\begin{array}{l}\text { Density of individual } \\
\text { disposition, ind./sq.m: } \\
\text { Plot N 4; N } 8\end{array}$} & \multicolumn{3}{|c|}{ Plot N 4} & \multicolumn{2}{|r|}{ Plot N 8} \\
\hline & & & $\boldsymbol{F}$ & $n$ & $M \pm \Delta ; C v, \% ; \operatorname{Lim} ; \sum x$ & $n$ & $M \pm \Delta ; C v, \% ; \operatorname{Lim} ; ; \sum x$ \\
\hline \multirow[t]{3}{*}{ Stolon } & June 28 & $16 ; 35$ & 1.36 & 16 & $4.0 \pm 0.61 ; 36 ; 2-7 ; 35$ & 35 & $2.9 \pm 0.47 ; 56 ; 1-7 ; 104$ \\
\hline & July 20 & 23,39 & 1.11 & 22 & $3.9 \pm 0.64 ; 45 ; 1-8 ; 86$ & 39 & $3.1 \pm 0.5 ; 60 ; 1-8 ; 122$ \\
\hline & August 13 & 24,45 & 1.21 & 20 & $4.4 \pm 0.57 ; 33 ; 2-8 ; 89$ & 38 & $3.4 \pm 0.44 ; 48 ; 1-7 ; 128$ \\
\hline \multirow{3}{*}{$\begin{array}{l}\text { Secondary } \\
\text { shoot-formation } \\
\text { center }\end{array}$} & June 28 & & $1.78^{*}$ & 16 & $13.6 \pm 3.84: 64 ; 3-32 ; 218$ & 35 & $10.1 \pm 1.8 ; 65 ; 1-29 ; 352$ \\
\hline & July 20 & & $1.81^{*}$ & 21 & $14.6 \pm 2.4 ; 44 ; 2-23 ; 308$ & 37 & $10.9 . \pm 2.4 ; 80 ; 2-31 ; 405$ \\
\hline & August 13 & & 1.17 & 24 & $15.9 \pm 2.8 ; 46 ; 4-29 ; 319$ & 38 & $11.0 \pm 1.27 ; 62 ; 2-27 ; 419$ \\
\hline \multirow{3}{*}{$\begin{array}{l}\text { Secondary } \\
\text { mineral-nutrition } \\
\text { center }\end{array}$} & June 28 & & 1.08 & 15 & $3.3 \pm 0.9 ; 72 ; 1-9 ; 59$ & 28 & $3.1 \pm 0.66 ; 65 ; 1-8 ; 89$ \\
\hline & July 20 & & $2.90 *$ & 19 & $5.9 \pm 1.4 ; 60 ; 2-17 ; 112$ & 28 & $3.7 \pm 0.66 ; 56 ; 1-8 ; 104$ \\
\hline & August 13 & & $1.96^{*}$ & 20 & $6.2 \pm 1.3 ; 54 ; 1-13 ; 125$ & 28 & $4.1 \pm 0.77 ; 58 ; 1-9 ; 128$ \\
\hline \multirow{3}{*}{$\begin{array}{l}\text { Generation } \\
\text { center }\end{array}$} & June 28 & & 1.14 & 16 & $7.18 \pm 1.7 ; 50 ; 3-17 ; 115$ & 33 & $6.2 \pm 1.05 ; 57 ; 1-16 ; 204$ \\
\hline & July 20 & & 1.16 & 20 & $4.6 \pm 0.94 ; 53 ; 1-9 ; 92$ & 36 & $3.9 \pm 0.74 ; 67 ; 1-12 ; 140$ \\
\hline & August 13 & & 1.41 & 17 & $2.8 \pm 0.62 ; 52 ; 1-6 ; 48$ & 27 & $2.8 \pm 0.57 ; 61 ; 1-8 ; 77$ \\
\hline $\begin{array}{l}\text { Nuts in the } \\
\text { combined fruit }\end{array}$ & July 20 & & 1.07 & 17 & $26.5 \pm 3.7 ; 32 ; 13-49 ; 451$ & 10 & $23.9 \pm 5.2 ; 38 ; 12-40 ; 239$ \\
\hline
\end{tabular}




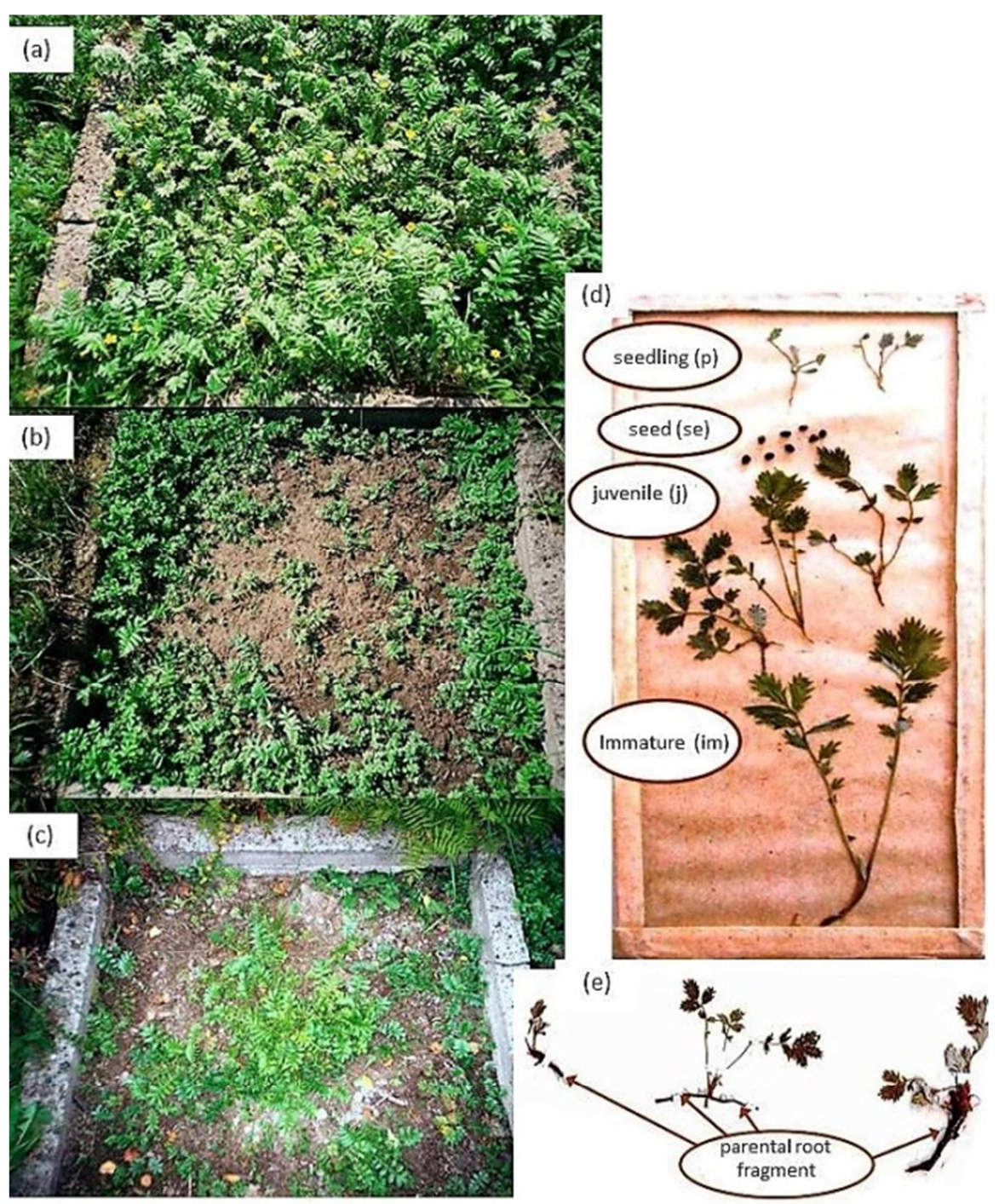

Figure 10. Potentilla anserina model population system at experimental plots and its resumption after the radical disturbance of the grass stand.

Plot N 10, June 12, 1998 (a); Plot N 5, July 18, 1998 (b); Plot N 5, September 15, 1998 (c); individuals from different ontogenetic groups (d); individuals - the product of organogenesis from the parental root fragment or hemorhizogenesis (e)

Table 10. Potentilla anserina model population system: Integral indicators. Data 1997-1998.

\begin{tabular}{|c|c|c|c|c|c|c|c|c|c|}
\hline \multirow{3}{*}{ Plot N } & \multirow{2}{*}{\multicolumn{3}{|c|}{$\begin{array}{l}\text { Density of individual disposition, } \\
\text { ind./sq.m }\end{array}$}} & \multicolumn{4}{|c|}{ Density of disposition, pes/sq.m: } & \multirow{3}{*}{$\begin{array}{l}\text { Length of the } \\
\text { network of } \\
\text { stolon, } \mathrm{m} / \mathrm{sq} . \mathrm{m}\end{array}$} & \multirow{3}{*}{$\begin{array}{l}\text { Aboveground live } \\
\text { phytomass in the } \\
\text { air-dry state, g/sq.m }\end{array}$} \\
\hline & & & & $\begin{array}{l}\text { generation } \\
\text { centers }\end{array}$ & $\begin{array}{l}\text { secondary shoot- } \\
\text { formation centers }\end{array}$ & $\begin{array}{l}\text { secondary mineral- } \\
\text { nutrition centers }\end{array}$ & stolon & & \\
\hline & $\begin{array}{l}\text { May 30, } \\
1996\end{array}$ & $\begin{array}{l}\text { June 5, } \\
1997 \\
\end{array}$ & \multicolumn{5}{|c|}{ Summer 1998: June 11 and August 1 (Plot N 5); July 10 (Plot N 1-4, 6-12) } & & \\
\hline & \multicolumn{7}{|c|}{ after planting model individuals } & & \\
\hline 1 & 1 & 56 & 295 & 261 & 367 & - & 118 & 27.16 & 99.7 \\
\hline 2 & 1 & 46 & 119 & 165 & 491 & 100 & 217 & 34.62 & 54.6 \\
\hline 3 & 1 & 30 & 83 & 317 & 323 & 66 & 128 & 19.01 & 34.9 \\
\hline 4 & 1 & 28 & 105 & 175 & 391 & 94 & 182 & 28.26 & 55.2 \\
\hline 5 & 5 & 71 & 962 & 657 & 0 & 0 & 215 & - & 195.38 \\
\hline 6 & 5 & 68 & 206 & 88 & 307 & 130 & 132 & 28.75 & 52.5 \\
\hline 7 & 5 & 46 & 123 & 149 & 362 & 110 & 172 & 31.5 & 46.5 \\
\hline 8 & 5 & 50 & 72 & 118 & 350 & 226 & 163 & 28.41 & 24.5 \\
\hline 9 & 9 & 57 & 300 & 340 & 1152 & 386 & 288 & 27.5 & 133.6 \\
\hline 10 & 9 & 23 & 301 & 314 & 325 & 147 & 155 & 24.96 & 153 \\
\hline 11 & 9 & 78 & 231 & 296 & 274 & 72 & 99 & 16.05 & 48.6 \\
\hline & 9 & 104 & 249 & 145 & 250 & 70 & 103 & 19.57 & 96.5 \\
\hline 12 & \multicolumn{8}{|c|}{ after a radical disturbance of the grass stand and provocation of the natural renewal of the population system } & \\
\hline 5 & & & 365 & 160 & 79 & 25 & 144 & 22.26 & 77.22 \\
\hline
\end{tabular}


An extremely dense stolon network $-34.62 \mathrm{~m} / \mathrm{sq} . \mathrm{m}$ is able to form in a population system with the density of individual disposition 119 ind./sq.m.

After a radical disturbance of the herbage and against the backdrop of favorable weather conditions, $P$. anserina population system is able to rapidly resume due to the process of organ regeneration from the educational tissue located at the point of damage to the root system (Figure 10). Thus, the fragment of $P$. anserina roots remaining in the soil play the role of plant vegetative diaspore, becoming clone parents. Thanks to this type of vegetative propagation after 1.5 months: 1) the density of individual disposition in the renewed $P$. anserina population system is able to reach 365 ind./sq.m, and the aerial dry living phytomass - $77.22 \mathrm{~g} / \mathrm{sq} . \mathrm{m} ; 2$ ) the morph-functional spectrum is able to manifest itself (Figure $11) ; 3$ ) the polycentric system is able to have 4 pcs stolon with a total length of up to $1.09 \mathrm{~m}$ or 7 pcs generation centers; 4) 66 ind. polycentric systems growing on an area of 1 sq.m are able to form 160 pcs of generation centers, and 84 ind. -144 pcs of stolon 5) other indicators of the population system are able to achieve the following values: the stolon network length $22.26 \mathrm{~m} / \mathrm{sq} . \mathrm{m}$; the secondary shoot-formation centers quantity - 79 pcs/sq.m; the secondary mineral-nutrition centers quantity -25 pcs/sq.m.
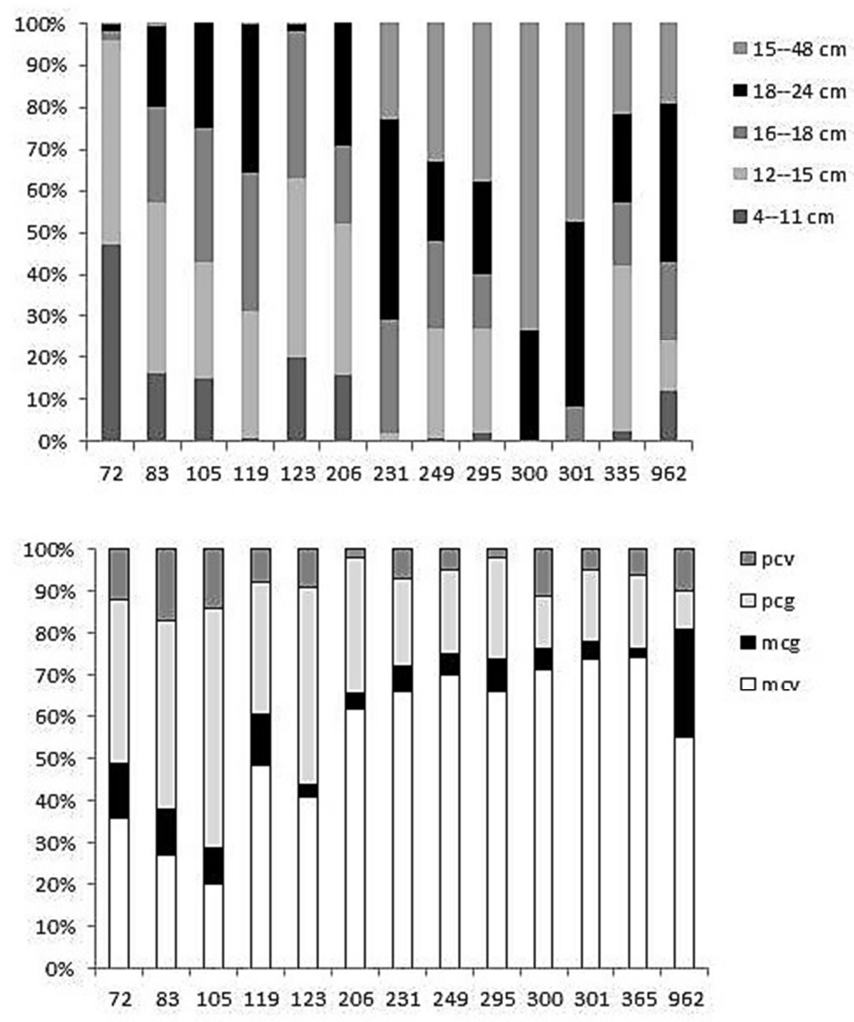

Figure 11. Potentilla anserina model population system: Spectra in the row an increase in the density of individual disposition. Data 1998.

Above is Morphological spectrum (Maximum length of plant leaves, $\mathrm{cm}$ ), Bottom is Morph-functional spectrum. On the horizontal is the individual disposition, ind./sq.m
Table 11. Potentilla anserina polycentric system: Metric indicators in the row an increase in the density of individual disposition. Data 1998.

\begin{tabular}{|c|c|c|}
\hline Quantity, pes: & $\begin{array}{l}\text { Density of individual } \\
\text { disposition, ind./sq.m } \\
\text { (Date) }\end{array}$ & $M \pm \Delta ; C v, \% ; \operatorname{Lim} ; n$ \\
\hline \multirow{11}{*}{ Stolon } & 72 (July 10) & $3.54 \pm 0.21 ; 44 ; 1-5 ; 45$ \\
\hline & 83 (July 10) & $2.13 \pm 0.11 ; 40 ; 1-3 ; 59$ \\
\hline & 105 (July 10) & $2.11 \pm 0.17 ; 76 ; 1-5 ; 61$ \\
\hline & 119 (July 10) & $3.6 \pm 0.28 ; 61 ; 2-8 ; 49$ \\
\hline & 123 (July 10) & $2.35 \pm 0.12 ; 44 ; 1-5 ; 73$ \\
\hline & 206 (July 10) & $1.68 \pm 0.07 ; 39 ; 1-3 ; 79$ \\
\hline & 231 (July 10) & $1.31 \pm 0.10 ; 68 ; 1-3 ; 63$ \\
\hline & 249 (July 10) & $1.36 \pm 0.10 ; 63 ; 1-3 ; 64$ \\
\hline & 295 (July 10) & $1.51 \pm 0.14 ; 50 ; 1-4 ; 78$ \\
\hline & 365 (August 1) & $1.71 \pm 0.16 ; 53 ; 1-4 ; 84$ \\
\hline & 962 (June 11) & $1.17 \pm 0.05 ; 36 ; 1-3 ; 184$ \\
\hline \multirow{10}{*}{$\begin{array}{l}\text { Secondary } \\
\text { shoot-formation } \\
\text { center }\end{array}$} & 72 (July 10) & $12.3 \pm 0.71 ; 38 ; 3-26 ; 45$ \\
\hline & 83 (July 10) & $5.42 \pm 0.38 ; 53 ; 2-12 ; 59$ \\
\hline & 105 (July 10) & $4.64 \pm 0.42 ; 82 ; 1-10 ; 61$ \\
\hline & 119 (July 10) & $8.04 \pm 0.65 ; 63 ; 4-20 ; 49$ \\
\hline & 123 (July 10) & $4.98 \pm 0.31 ; 54 ; 1-10 ; 73$ \\
\hline & 206 (July 10) & $3.86 \pm 0.24 ; 56 ; 1-9 ; 79$ \\
\hline & 231 (July 10) & $3.6 \pm 0.29 ; 70 ; 1-9 ; 63$ \\
\hline & 249 (July 10) & $3.1 \pm 0.30 ; 84 ; 1-15 ; 64$ \\
\hline & 295 (July 10) & $4.8 \pm 0.66 ; 65 ; 1-13 ; 78$ \\
\hline & 365 (August 1) & $2.13 \pm 0.30 ; 50 ; 1-4 ; 37$ \\
\hline \multirow{6}{*}{$\begin{array}{l}\text { Secondary } \\
\text { mineral-nutrition } \\
\text { center }\end{array}$} & 72 (July 10) & $3.89 \pm 0.33 ; 58 ; 1-10 ; 45$ \\
\hline & 83 (July 10) & $1.11 \pm 0.13 ; 38 ; 1-4 ; 59$ \\
\hline & 105 (July 10) & $1.63 \pm 0.18 ; 88 ; 1-7 ; 49$ \\
\hline & 119 (July 10) & $1.5 \pm 0.14 ; 81 ; 1-5 ; 67$ \\
\hline & 123 (July 10) & $1.62 \pm 0.12 ; 70 ; 1-5 ; 79$ \\
\hline & 206 (July 10) & $1.66 \pm 0.32 ; 43 ; 1-3 ; 15$ \\
\hline \multirow{11}{*}{$\begin{array}{l}\text { Generation } \\
\text { center }\end{array}$} & 72 (July 10) & $2.58 \pm 0.22 ; 56 ; 1-6 ; 43$ \\
\hline & 83 (July 10) & $5.38 \pm 0.24 ; 35 ; 2-8 ; 59$ \\
\hline & 105 (July 10) & $2.05 \pm 0.13 ; 59 ; 1-5 ; 84$ \\
\hline & 119 (July 10) & $2.7 \pm 0.20 ; 58 ; 1-6 ; 61$ \\
\hline & 123 (July 10) & $1.98 \pm 0.12 ; 52 ; 1-5 ; 71$ \\
\hline & 206 (July 10) & $1.12 \pm 0.05 ; 41 ; 1-3 ; 76$ \\
\hline & 231 (July 10) & $3.89 \pm 0.23 ; 52 ; 1-9 ; 76$ \\
\hline & 249 (July 10) & $2.01 \pm 0.12 ; 51 ; 1-4 ; 75$ \\
\hline & 295 (July 10) & $2.77 \pm 0.38 ; 81 ; 1-12 ; 94$ \\
\hline & 365 (August 1) & $2.4 \pm 0.35 ; 71 ; 1-4 ; 66$ \\
\hline & 962 (June 11) & $1.96 \pm 0.09 ; 56 ; 1-6 ; 335$ \\
\hline
\end{tabular}

The results of three-year observations of Potentilla anserina model population system of allow us to recognize the endogenous factor of the density of individual disposition as basic, since this determines both the rate of development of individuals and the rate of herbage renewal after its radical disturbance.

\subsection{Final Position}

A field diary, made on the basis of a well-posed experiment with a living plant in an environment close to the natural for this plant, has no statute of limitations. The methodological apparatus of the researcher is being improved. In this regard, at different stages of the study, discoveries of unknown facts from the plant life and the discovery of plant population system development laws are possible. It is almost impossible to repeat the field experiment with the plant because of the large amount of work that is required to conduct it, because of differences in the temperature background and differences in the rhythm of precipitation. Therefore, each field experiment 
is unique and the scientific result from it is also unique. In this regard, modern researchers should be careful about their field diaries and leave their electronic version for the next generation of researchers.

\section{Perfection}

Despite the fact that Concept "Polycentric Mode of Plant" was formed recently, on its basis I was able to develop a number of methodological approaches that are suitable for solving various problems of Population Botany and Plant Ecology. The principles of population study of plants, formulated on the basis of the Concept, emphasize the feasibility of involving gifted children in the research process, as this will not entail a decrease in the quality of research work.

The simplicity of Polycentric Model of Plant and the clear criteria of its elements reduce the likelihood of subjective errors in the process of plant description, and this circumstance will contribute to a deeper interaction between scientists from different botanical traditions.

I cannot be sure that in the near future I will not have to solve a new environmental problem. And if this happens, and the existing methods do not allow finding the most rational solution to the problem, then Concept "Polycentric Model of Plant" will come to my aid again.

\section{Acknowledgements}

New theories in the head of a scientist are not born accidentally. There is always a person, after communicating with whom the scientist begins to form a protest of a methodological approach to solving the obvious problems. Such persons in their words and actions without noticing themselves, cause a powerful impulse after which the worldview of the scientist changes.

In my life there were several such personalities. I thank fate for having been given a meeting with them. I want to thank them publicly. I will mark in parentheses those sections in my publication, on the elements of which I thought about by communicating with them. Scientists in the field of population botany and the ecology of plants and my teachers (Russian Federation, Kazan): Evgeny Leonidovich Lyubarsky and Valentina Ivanovna Poluyanova (Section: 3, $5,7)$. Scientist in plant bio-morphology and my opponent (Russian Federation, city of Kirov) Natalia Pavlovna Savinykh (Sections 2 and 3). The teacher in botany and my colleague (Russian Federation, Kazan): Lyaylya Usmanovna Mavlyudova (Sections 4 and 5). The young scientist in the field of geobotany (Mongolia) and a former graduate student at the department, which is my workplace by: Urtnasan Mandakh (Section 6).

I was able to convey all my thoughts to you, dear like-minded people and opponents, only thanks to the fact that I had the opportunity to sharpen my English in communication with Carlos James Robles, who is on a mission under the aegis of the UN in one of the dangerous zones. And I also thank him for his moral support.

The work was carried out in accordance with the State Program of the Russian Federation "Enhancing the Competitiveness of the Kazan Federal University".

\section{Conflict of Interest}

Author confirms that the data does not contain any conflict of interest.

\section{References}

[1] V. I. Plujanova and S. V. Fedorova, "The experience of growing Potentilla anserina L. in experimental plantings (Tatarstan Republic)," Rastitelnye Resursy, vol. 1, 2002, pp. 57-64.

[2] V. I. Plujanova and S. V. Fedorova, "Experimental studies of clone formation Trifolium repens L. (Fabaceae)," Rastitelnye Resursy, vol. 4, 2004, pp. 50-55.

[3] S. V. Fedorova, "Structure and organization of populations of a number of terrestrial-creeping plants in different ecological-phytocenotic conditions," Dissertation... PhD of Biologic, Russia, Kazan: KGU, 2007, 223 (in Russian).

[4] S. V. Fedorova, "Variety of forms and allometric parameters of the triple leaf Ranunculus repens L.," Sc. J., Vestnik of the Tver State University, Series biology, ecology, vol. 9, N. 25 (85), Russia, Tver, 2008, pp. 267-271.

[5] S. V. Fedorova, "Potential growth opportunities for some terrestrial-creeping plants in model populations," Sc. J., Almanac of modern science and education, vol. 5, Russia, Tambov: Gramota, 2008, pp. 126-129.

[6] S. V. Fedorova, "Analysis of morph-functional spectra in model populations of terrestrial-creeping plants," Sc. J., Proceedings of Institute of Botany MAS, vol. 21, Mongolia, Ulaanbaatar, 2009, pp. 179-187.

[7] S. V. Fedorova, "Population responses of Fragaria vesca L. (Rosaceae) to the change of ecological-phytocenotic factors," Sc. J., Proceedings of the Tigirek Reserve, vol. 3, Russia, Barnaul, 2010. pp. 160-165.

[8] S. V. Fedorova, "Features of the formation of Ranunculus repens L. (Ranunculaceae) polycentric system in the model population," Sc. J., Problems of Botany of Southern Siberia and Mongolia, vol. 11, Russia, Barnaul, 2012, pp. 201-206.

[9] S. V. Fedorova, "Reactions of Galium odoratum (L.) Scop. (Rubiaceae) to replace habitat conditions," Sc. J., Izvestiya of the Samara Scientific Center of the Russian Academy of Sciences, vol. 14 (7), Russian, Samara, 2012, pp. 1872 1878 .

[10] S. Fedorova, Population organization of herbaceous plants in forest phytocenosis: Asarum europaeum L. (Aristolochiaceae) and Convallaria majalis L. (Convallariaceae). Germany, Saarbrucken: LAP LAMBERT Academic Pablishing GmbH \& Co. KG, 2013, 116 (in Russian).

[11] S. V. Fedorova, "Asarum europaeum L. (Aristolochiaceae) cenopopulations in forest: Responses to climatic factor," Research Journal of Pharmaceutical, Biological and Chemical Sciences, vol. 6, N. 4, 2015, pp. 2106-211. 
[12] S. V. Fedorova. "Methodological bases of population research of plants with vegetative reproduction," in 5-th All-Russian Geobotanical school-conf. with Intern. participation (St. Petersburg, October 4-9, 2015), Russia, St. Petersburg: St.-PbSU, 2015, p. 53.

[13] S. V. Fedorova, "Aster alpinus L. (Asteraceae) on the slopes of different exposures: the population aspect," Sc. J., Proceedings of the Tigirek Reserve, vol. 7, Russia, Barnaul, 2015. pp. 191198.

[14] S. V. Fedorova, "Seasonal rhythm of the development of polycentric systems in the coenopopulation Convallaria majalis L. (Convallariaceae)," Sc. J., Bull. Garden-Institute of Far East Branch of RAS, vol. 14, Russia, Vladivostok, 2015, pp. $11-27$.

[15] S. V. Fedorova, "Asarum europaeum L. (Aristolochiaceae): polycentric model of the structure of the organism, morphometry, productivity," Sc. J., Problems of Botany of Southern Siberia and Mongolia, vol. 14, Russia, Barnaul, 2015, pp. 308-313.

[16] S. V. Fedorova, "Polycentric Model of Plant - as a tool for the diagnosis of the population system," in Modern concepts of the ecology of bio-systems and their role in solving problems of nature conservation and nature management, 2016., Russia, Penza: PSU, pp. 188-191.

[17] S. V. Fedorova, "Principles of population studies plants are capable of vegetative reproduction," in Ecological research of local flora, Russia, Ishim: IshimPI, 2016, pp. 73-80.

[18] S. V. Fedorova, "Experimental results with Ranunculus repens L. (Ranunculaceae) in the concept "Polycentric plant model," in Systematic and floristic studies of Northern Eurasia: proceedings of the 2-nd International Conference (on the 90-th birthday of Professor A. G. Yelenevsky), vol. 3, Russia, Moscow: MSPU, 2018, pp. 84-88.

[19] S. V. Fedorova, "Methodology the population of plants in the diagnosis of the state of vegetation elements," Sc. J., Samarskaya Luka: problems of regional and global ecology, vol. 27, N 4 (1), Russia, Samara, 2018, pp. 50-59. DOI: 10.24411/2073-1035-2018-10090

[20] S. V. Fedorova, "Methodological bases of population research of herbaceous plants in forest phytocenoses," Sc. J., Botanical research in Siberia, vol. 26, Russia, Krasnoyarsk, 2018, pp. 98111.
[21] S. V. Fedorova, "Dominants of the steppe pastures of Mongolia: the population aspect," in Problems of population biology: materials of the XII All-Russian Population Seminar in memory of N. V. Glotov (Yoshkar-Ola, April 11-14, 2017), Russia, Yoshkar-Ola: String, 2017, pp. 241-244.

[22] S. V. Fedorova, "Dominant of the steppe pastures of Mongolia - Stipa krylovii Roshev. (Poaceae): population aspect," Sc. J., Problems of Botany of Southern Siberia and Mongolia, vol. 16, Russia, Barnaul, 2017, pp. 161-165.

[23] S. V. Fedorova, "Potentilla astragalifolia Bunge (Rosaceae) in the steppe pastures of Mongolia: population aspect," in Steppes of Northern Eurasia: Proceedings of the 8-th International Symposium, Russia, Orenburg: Institute of Steppe UB RAS, 2018, pp. 1036-1039.

[24] S. V. Fedorova, "Development peculiarities of some plants in the steppe pastures of Central Mongolia," Sc. J., Problems of Botany of Southern Siberia and Mongolia, vol. 18, Russia, Barnaul, 2019, pp. 428-433. DOI: 10.14258/pbssm.2019088

[25] S. V. Fedorova and Ts. Batseren, "Population organization Ephedra sinica Stapf. (Ephedraceae) in the steppes of the Eastern Mongolia," in Problems of Botany of Southern Siberia and Mongolia, Russia, Barnaul: Altaisky SU, 2009, pp. 265-273.

[26] Actual problems of modern bio-morphology. N. P. Savinyich, Eds. Russia, Kirov: Raduga Press, 2012, 610 (in Russian).

[27] M. Urtnasan, "Pasture digression in the steppes of the northern part of Central Mongolia," Dissertation... PhD of Biologic, Russia, Kazan: K (P) FU, 2015. 167 (in Russian).

[28] E. L. Lyubarsky, "About rating projective cover of grass component," Russian Journal of Ecology, vol. 1, 1974, pp. 9899.

[29] A. A. Uranov, "Age-related spectrum of phytocenopopulations as a function of time and energy wave processes." Sc. J., Scientific reports of higher education. Biol. Sciences. vol. 2, Russia, Moscow, 1975, pp. 7-34 (in Russian).

[30] L. A. Zhukova, "Ontogenesis and reproduction cycles of plants," Sc. J., Journal of General Biology, vol. 44, N 3, USSR, Moscow, 1983, pp. 361-374 (in Russian).

[31] Yu. A. Zlobin, "Theory and practice of assessing the vitality composition of coenopopulations of plants," Sc. J., Botanical journal, vol. 74, N 6, Russia, Moscow, 1989, pp. 76-784 (in Russian). 